\title{
Diversity-Oriented Synthesis of Imidazo-Dipyridines with Anticancer Activity via \\ Groebke-Blackburn-Bienaymé and TBAB-Mediated Cascade Reaction in One Pot
}

Yong Li,${ }^{\dagger}$ Jiu-Hong Huang, ${ }^{\dagger}$ Juan-Li Wang, ${ }^{\dagger}$ Gui-Ting Song, ${ }^{\dagger}$ Dian-Yong Tang, ${ }^{\dagger}$ Fang Yao, ${ }^{\dagger}$ Hui-Kuan Lin, ${ }^{\$}$ Wei Yan, ${ }^{\ddagger}$ Hong-yu Li, ${ }^{\ddagger}, *$ Zhi-Gang Xu, ${ }^{\dagger} * *$ Zhong-Zhu Chen ${ }^{\dagger, *}$

$\dagger$ International Academy of Targeted Therapeutics and Innovation, Chongqing University of Arts and Sciences. 319 Honghe Ave., Yongchuan, Chongqing, 402160, China

¥ Department of Pharmaceutical Sciences, College of Pharmacy, University of Arkansas for Medical Sciences, Little Rock, AR 72205, USA

${ }^{\$}$ Department of Cancer Biology, Wake Forest School of Medicine, Winston-Salem, NC, 27157, USA

Content

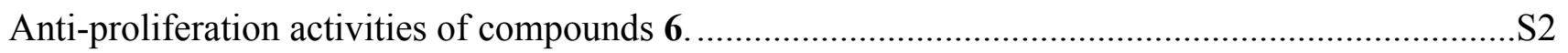

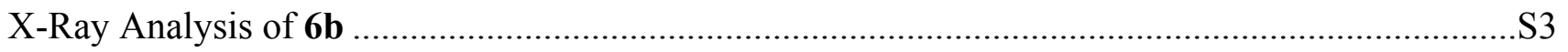

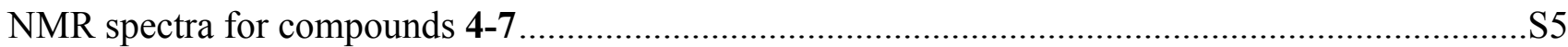




\section{Anti-proliferation activities of compounds 6.}

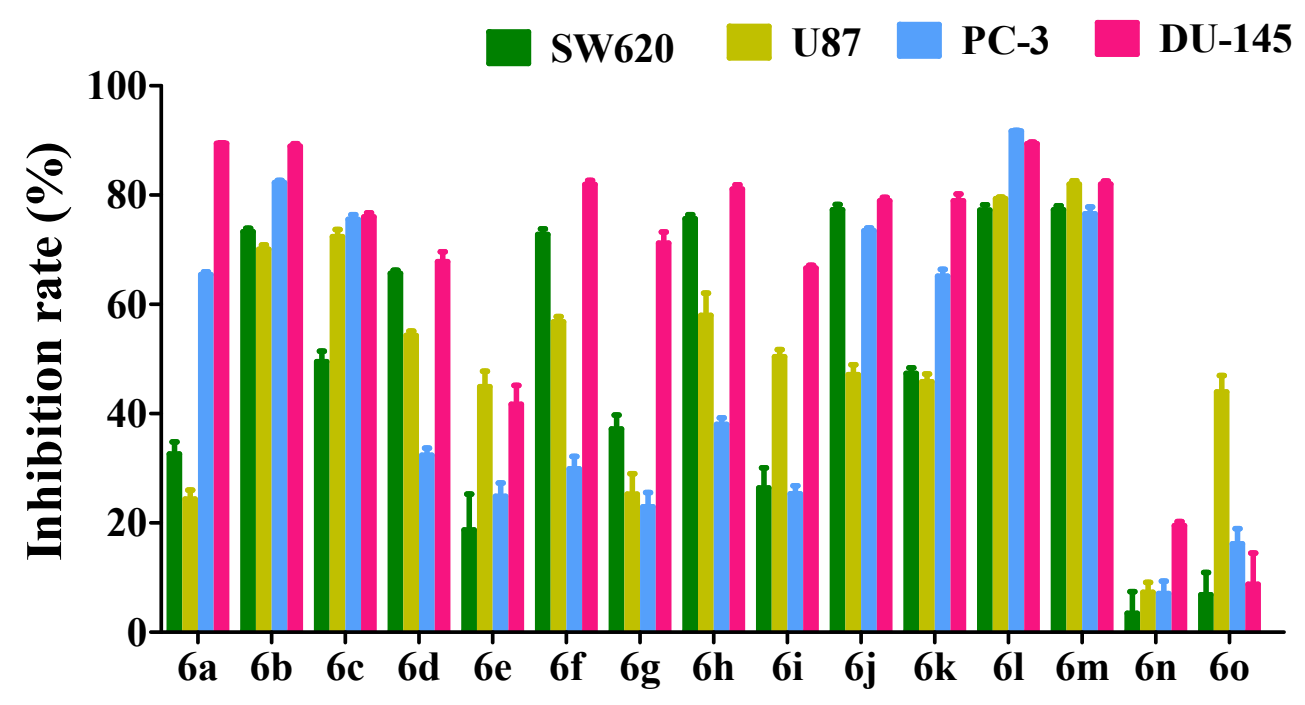

Figure S1. Anti-proliferation activities of compounds 6. Compounds 6 inhibit tumor cell proliferation. SW620, U87, PC-3 and DU-145 cells were treated with compounds 6 at the concentration of $10 \mu \mathrm{M}$ for $48 \mathrm{~h}$, and then cell viability was measured and calculated with MTT assay. Bar figure shows cell growth inhibition rate compared with control. Data is mean $\pm \mathrm{SD}$ of three independent experiments, each experiment was conducted in sextuplicate. 


\section{X-Ray Analysis of $6 \mathrm{~b}$}

Single crystal X-ray diffraction experimental

Single crystals of $\mathbf{6 b}$ were grown from methanol/dichloromethane at room temperature by slow evaporation. Crystallographic studies were undertaken on single crystal mounted on Broker Apex II diffractometer with Apex II CCD Detector, Cu-Microsource and Oxford Cryosystem 700 Plus low temperature Device. The structure has been deposited with the Cambridge Structural Database (CCDC deposition numbers 1907307). These can be obtained free of charge from the Cambridge Crystallographic Data Centre via www.ccdc.cam.ac.uk/data_request/cif.

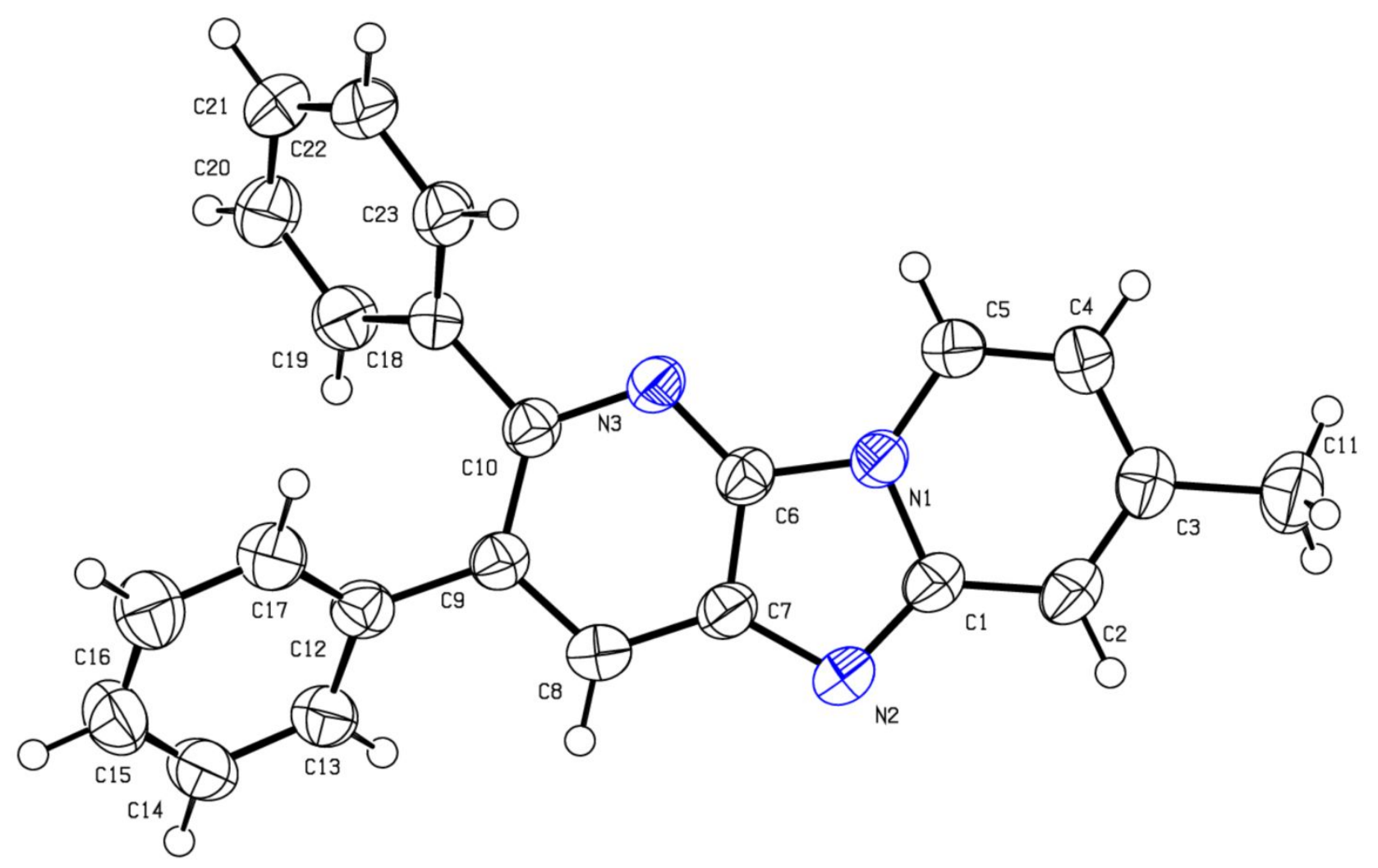

Figure S2. Solid-state structure of $\mathbf{6 b}$. C: black, N: blue. H atoms are omitted for clarity. Thermal ellipsoids shown at $50 \%$ probability. 
Table S1. Crystal data and structure refinement for compound $\mathbf{6 b}$.

\begin{tabular}{ll}
\hline Identification code & Compound $\mathbf{6 b}$ \\
\hline Empirical formula & $\mathrm{C}_{23} \mathrm{H}_{17} \mathrm{~N}_{3}$ \\
Formula weight & 335.39 \\
Temperature/K & 293.15 \\
Crystal system & monoclinic \\
Space group & $\mathrm{P} 2_{1} / \mathrm{c}$ \\
$\mathrm{a} / \AA$ & $8.8801(4)$ \\
$\mathrm{b} / \AA$ & $10.4479(5)$ \\
$\mathrm{c} / \AA$ & $19.1470(10)$ \\
$\alpha /{ }^{\circ}$ & 90 \\
$\beta /{ }^{\circ}$ & $91.163(4)$ \\
$\gamma /{ }^{\circ}$ & 90 \\
Volume/ $\AA^{3}$ & $1776.06(14)$ \\
$\mathrm{Z}$ & 4 \\
$\rho_{\text {calcg/cm }}{ }^{3}$ & 1.254 \\
$\mu /$ mm $^{-1}$ & 0.075 \\
$\mathrm{~F}(000)$ & 704.0 \\
Crystal size/mm & \\
Radiation & $0.4 \times 0.35 \times 0.3$ \\
$2 \Theta$ range for data collection/ & \\
Index ranges & MoK $\alpha(\lambda=0.71073)$ \\
Reflections collected & 6.196 to 52.744 \\
Independent reflections & $-11 \leq \mathrm{h} \leq 10,-12 \leq \mathrm{k} \leq 13,-23 \leq 1 \leq 12$ \\
Data/restraints/parameters & 7970 \\
Final R indexes [all data] & $3625\left[\mathrm{R}_{\text {int }}=0.0199, \mathrm{R}_{\text {sigma }}=0.0358\right]$ \\
\hline
\end{tabular}


NMR spectra for compounds 4-7

${ }^{1}$ H-NMR for compound 4a

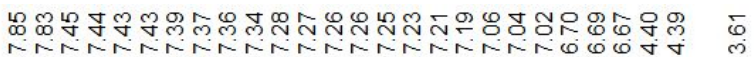
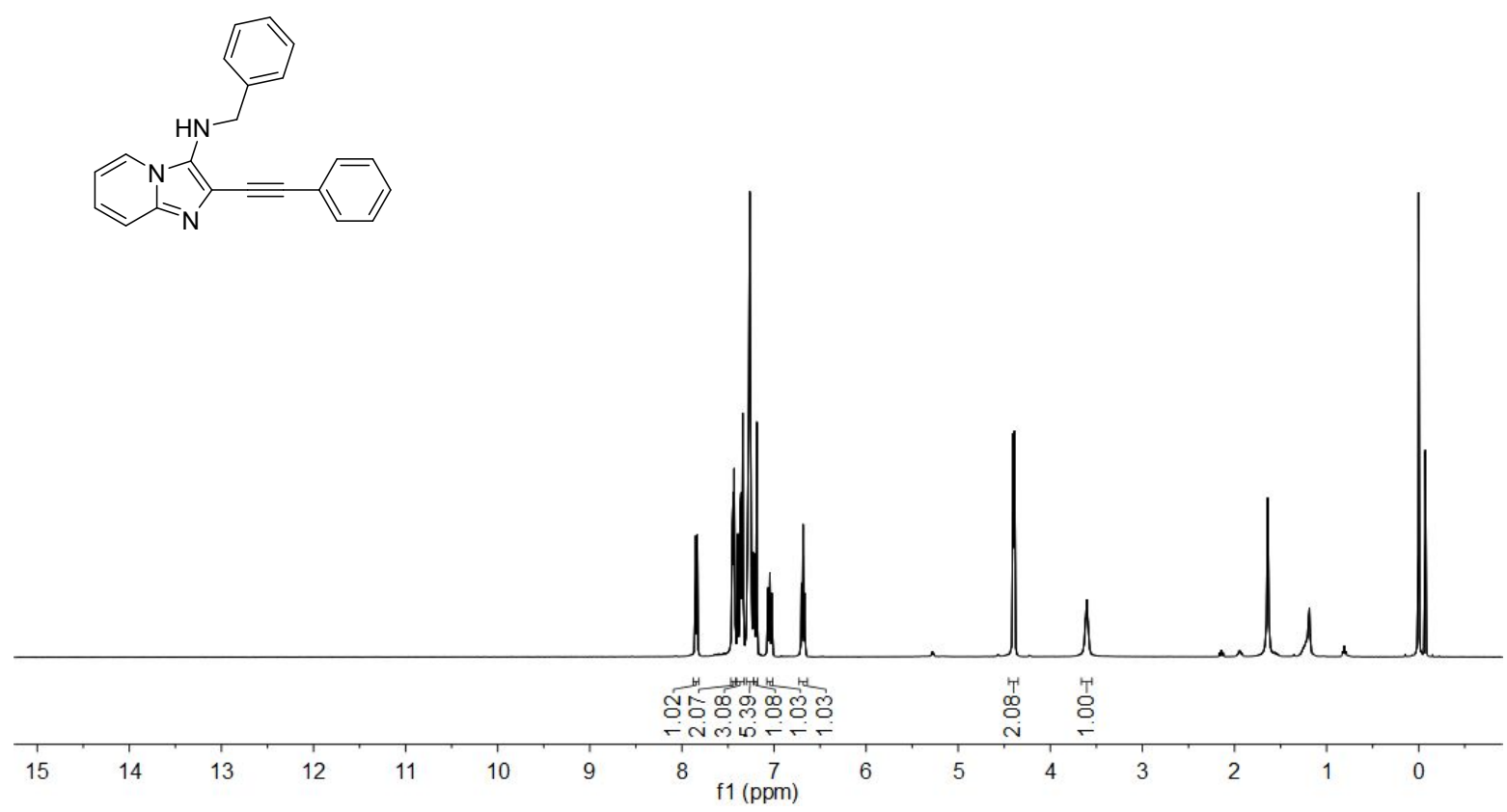

${ }^{13} \mathrm{C}$-NMR for compound $4 a$

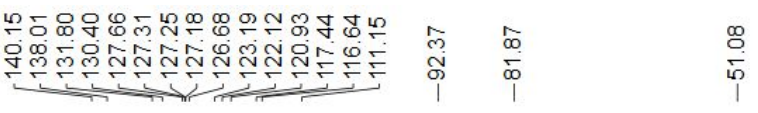
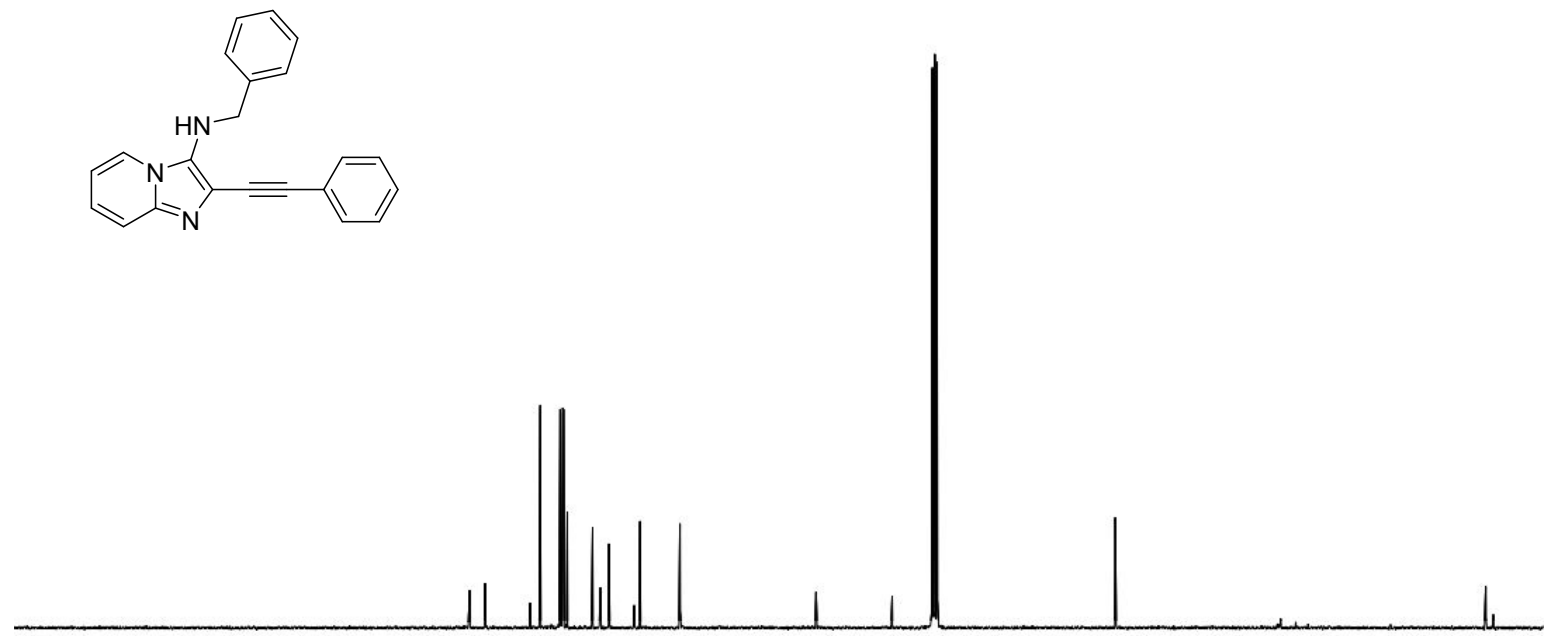

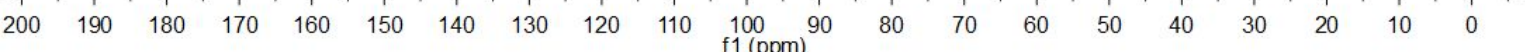


${ }^{13}$ C-NMR-DEPT135 for compound 6a

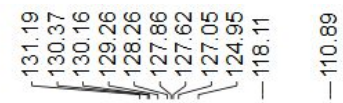

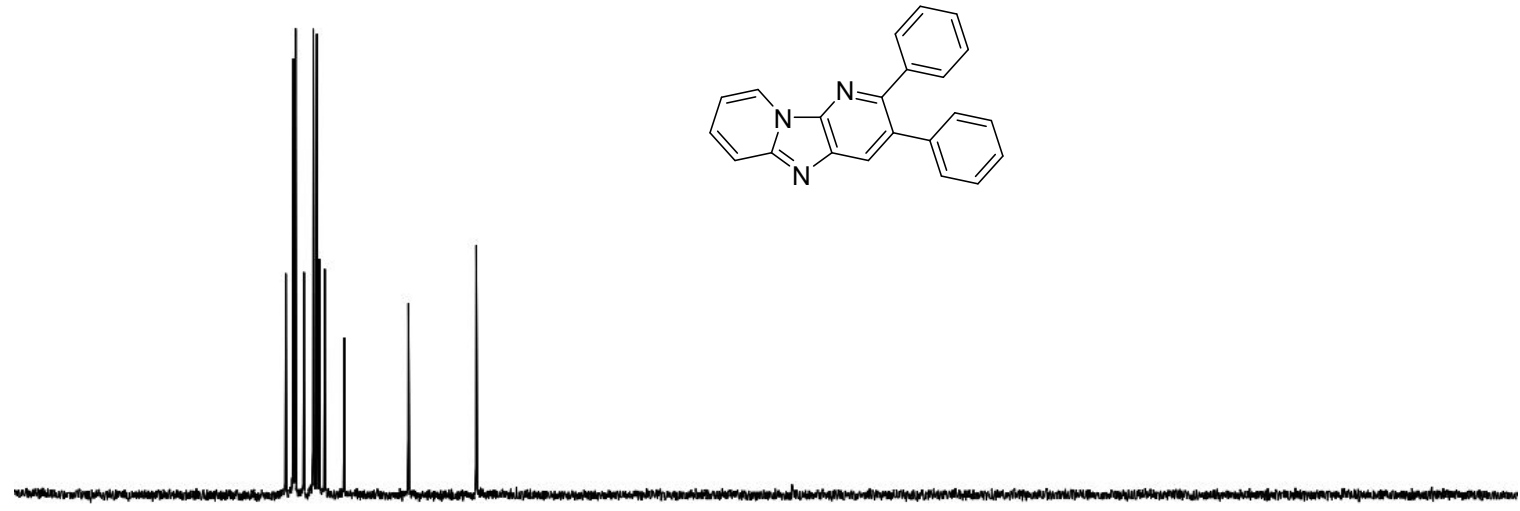

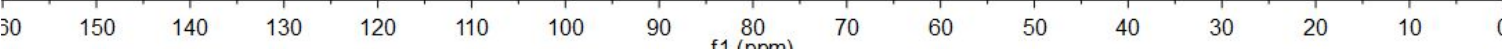


${ }^{1}$ H-NMR for compound 6a
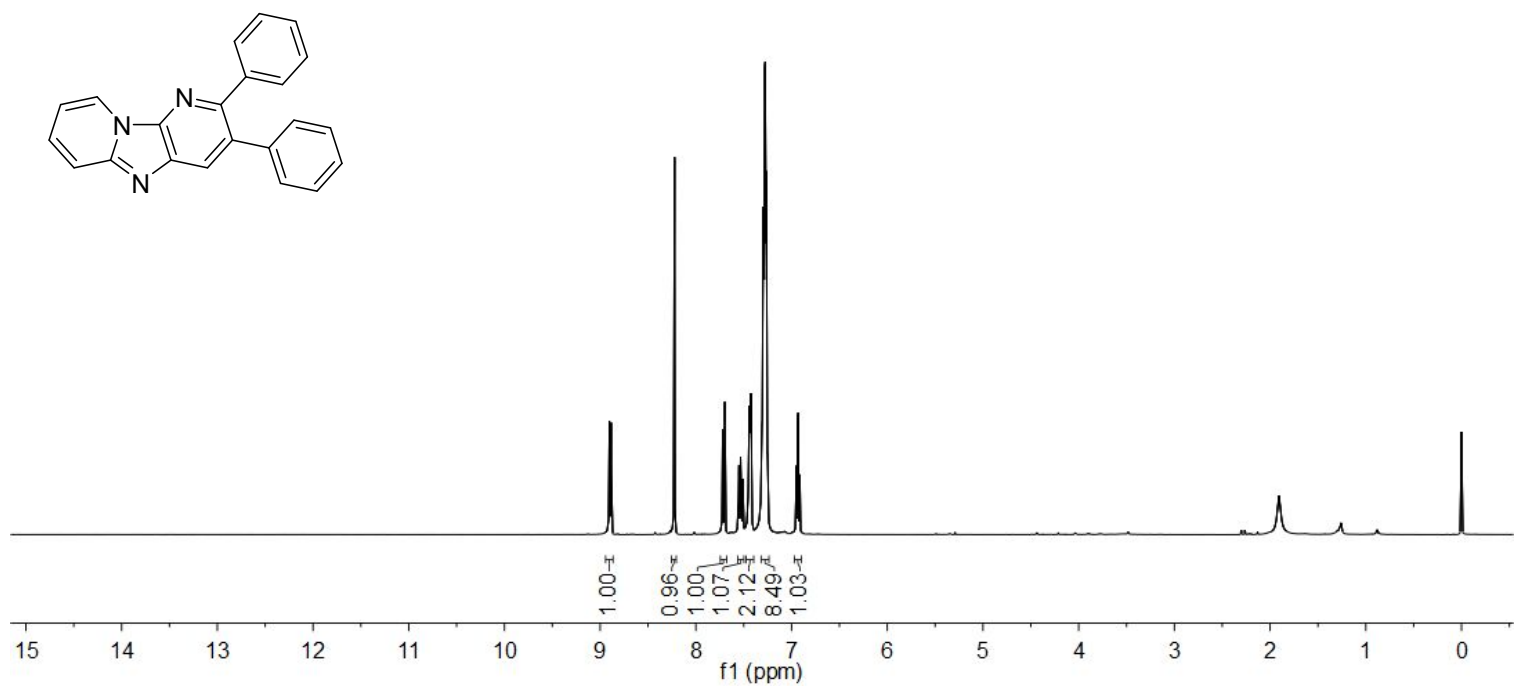

\section{${ }^{13} \mathrm{C}-\mathrm{NMR}$ for compound $6 \mathrm{a}$}

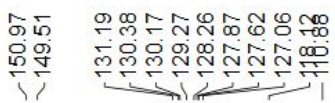
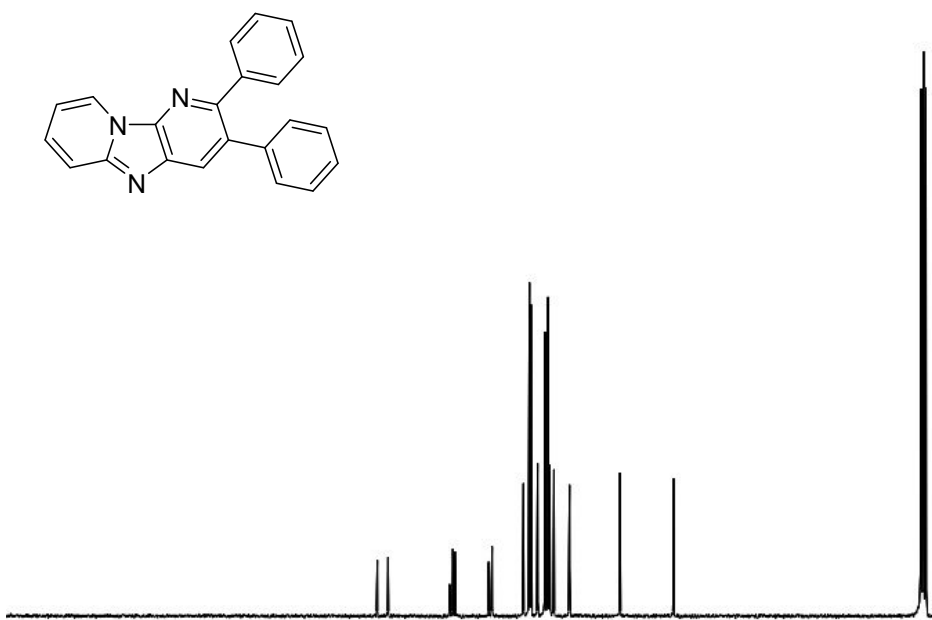

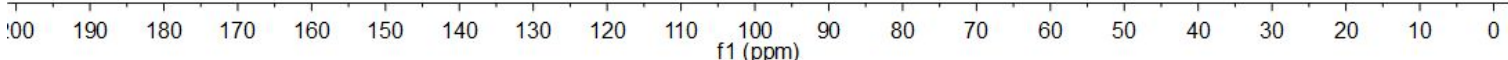


${ }^{1}$ H-NMR for compound $6 b$
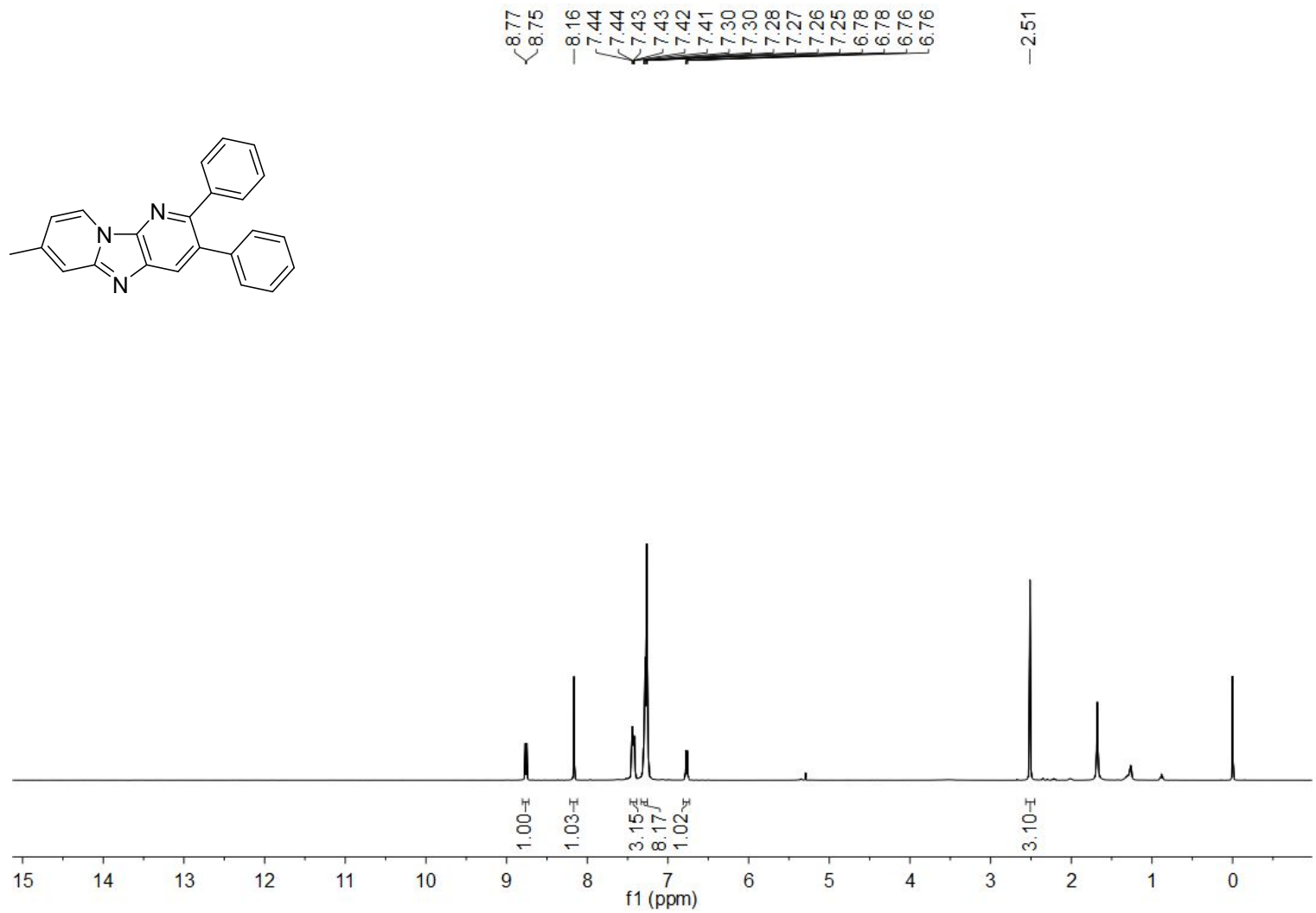

${ }^{13} \mathrm{C}-\mathrm{NMR}$ for compound $6 \mathrm{~b}$

깅

ํํㅇ 은

$\stackrel{\text { ก }}{\text { ก }}$
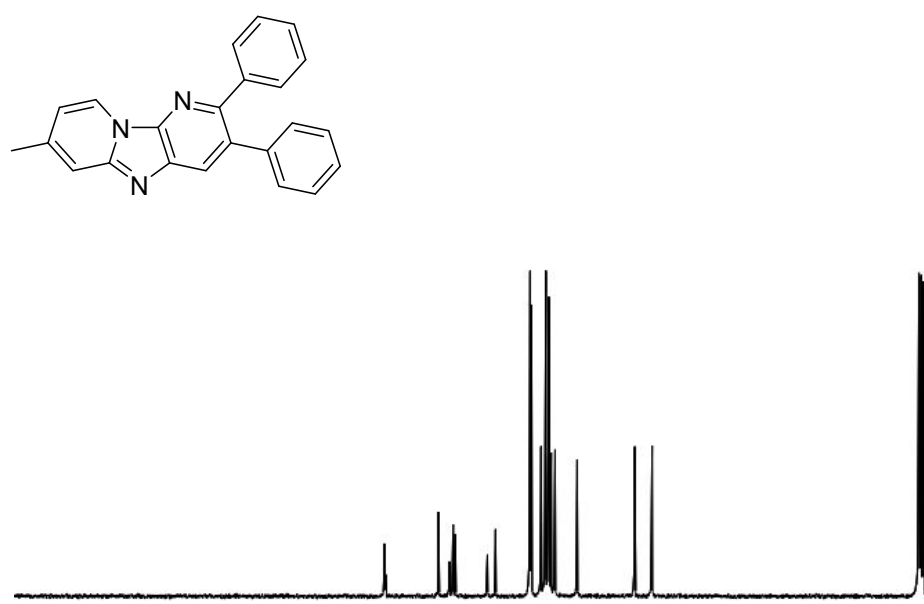

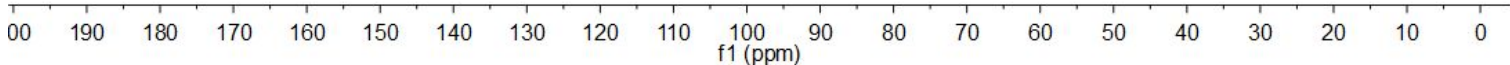


${ }^{1}$ H-NMR for compound 6c<smiles>Brc1cccn2c1nc1cc(-c3ccccc3)c(-c3ccccc3)nc12</smiles>

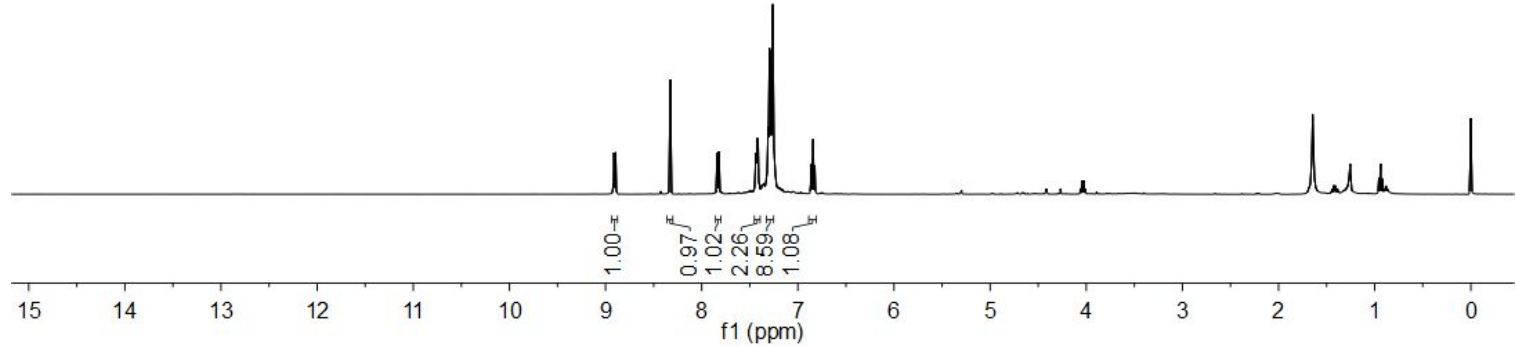

\section{${ }^{13} \mathrm{C}$-NMR for compound $6 \mathrm{c}$}
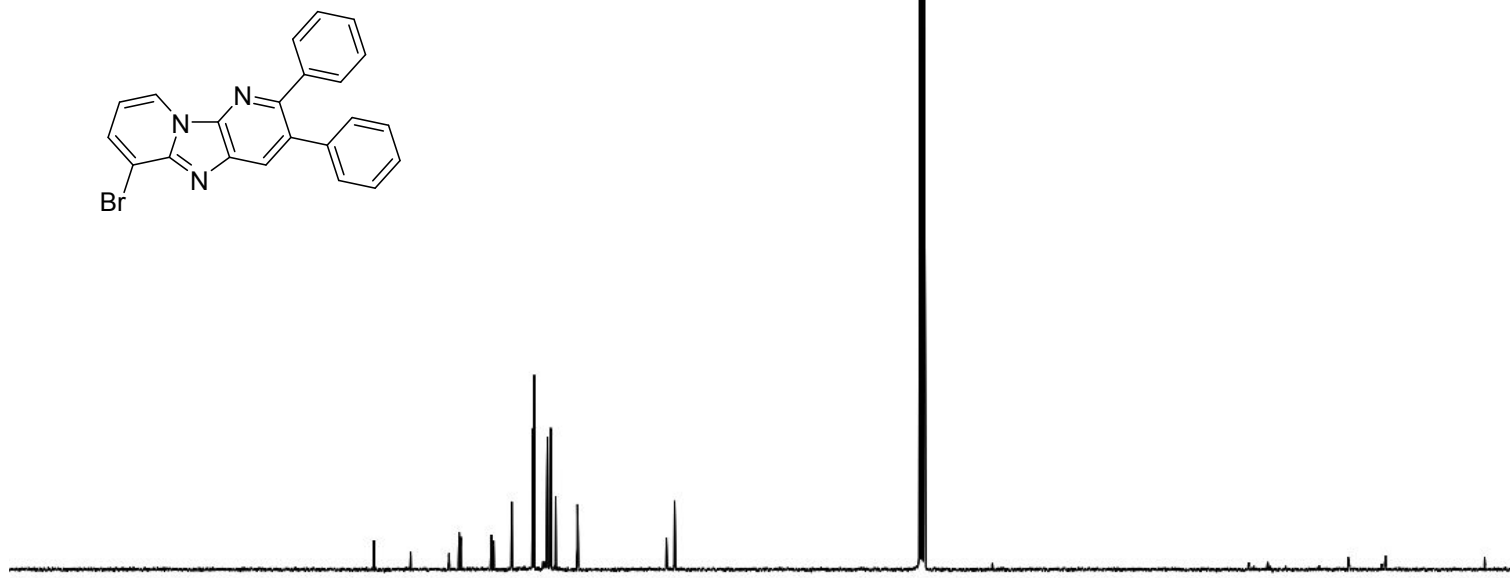

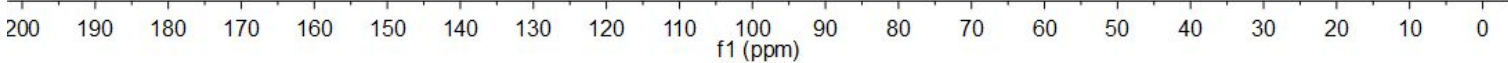


${ }^{1}$ H-NMR for compound 6d<smiles>Cc1cc(Br)c2nc3cc(-c4ccccc4)c(-c4ccccc4)nc3n2c1</smiles>

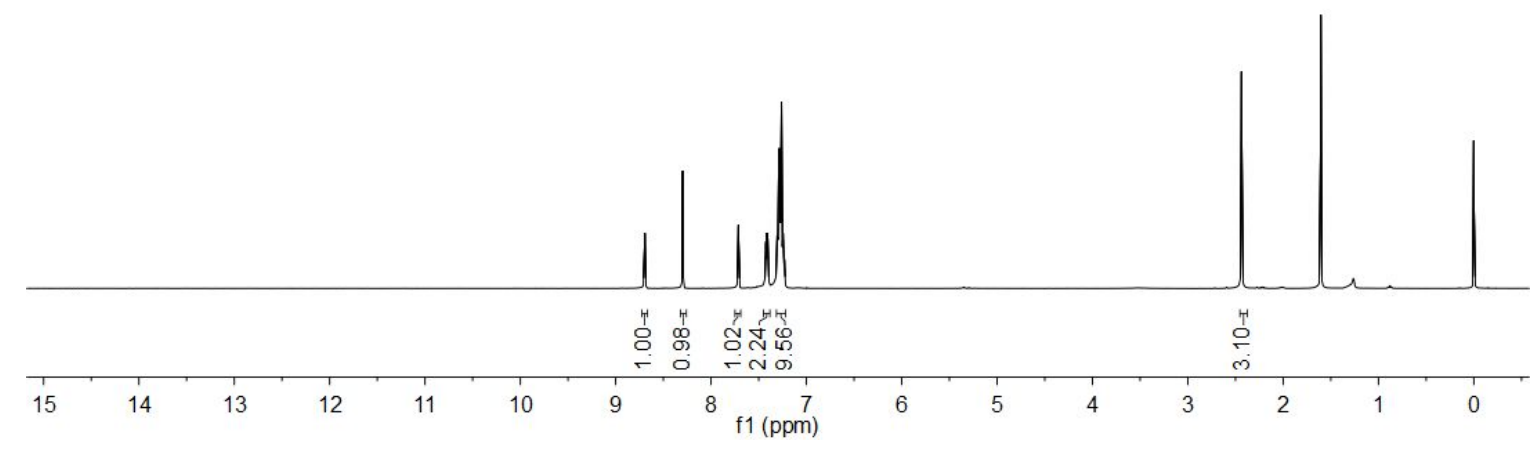

${ }^{13}$ C-NMR for compound 6d

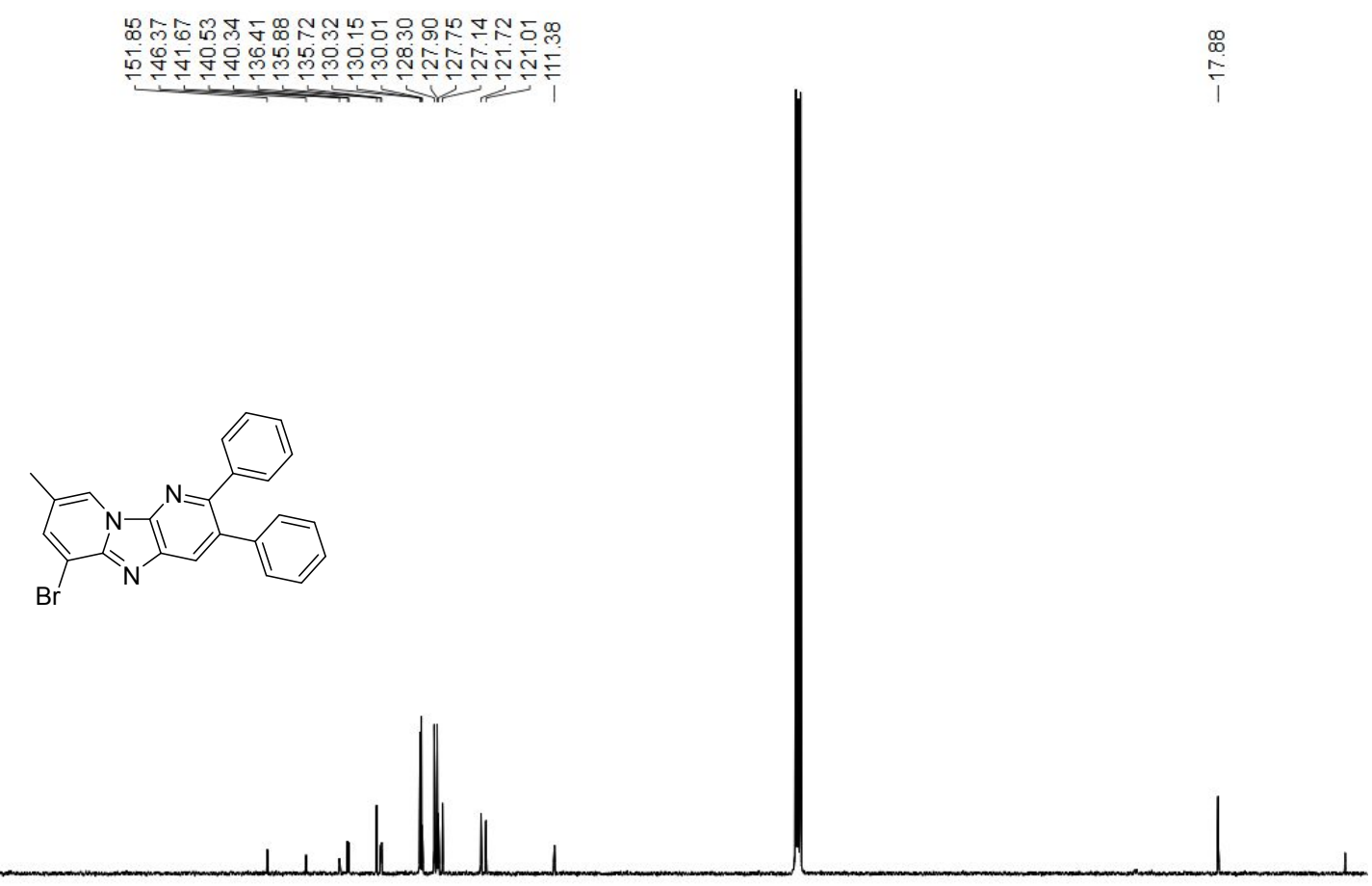

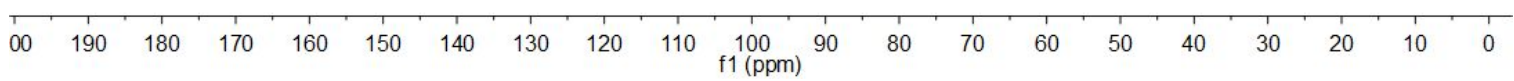


${ }^{1}$ H-NMR for compound 6e

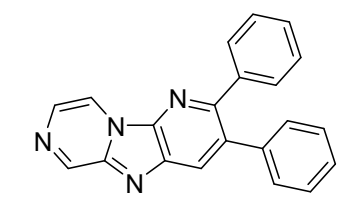

luml

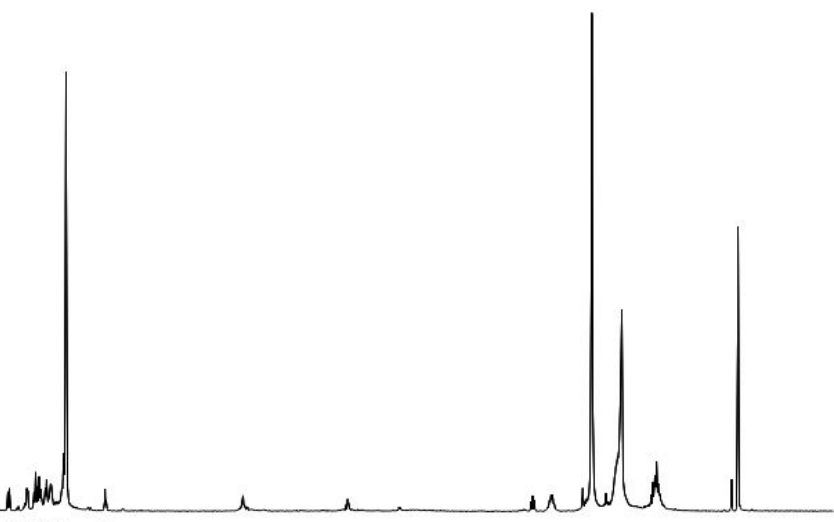

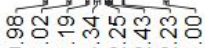

$\begin{array}{lllll}15 & 14 & 13 & 12 & 11\end{array}$

$1, \frac{1}{1}$

${ }^{13} \mathrm{C}-\mathrm{NMR}$ for compound $6 \mathrm{e}$

焉<smiles>c1ccc(-c2cc3nc4cnccn4c3nc2-c2ccccc2)cc1</smiles>

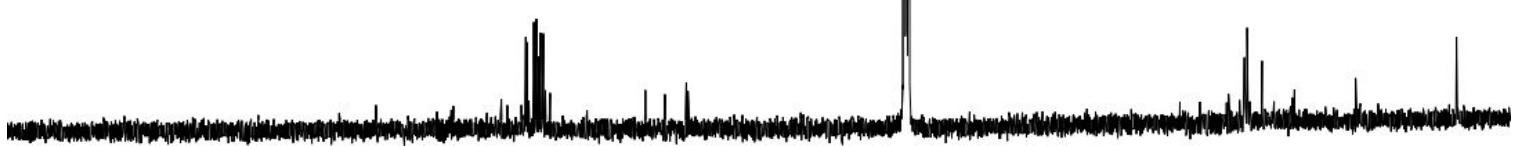

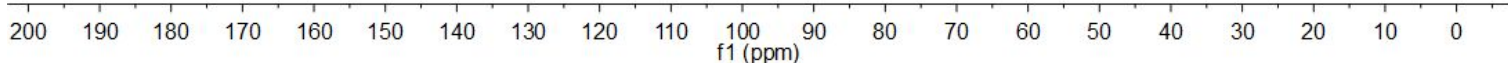


${ }^{1}$ H-NMR for compound $6 f$

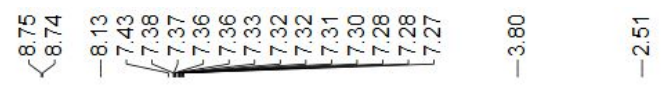
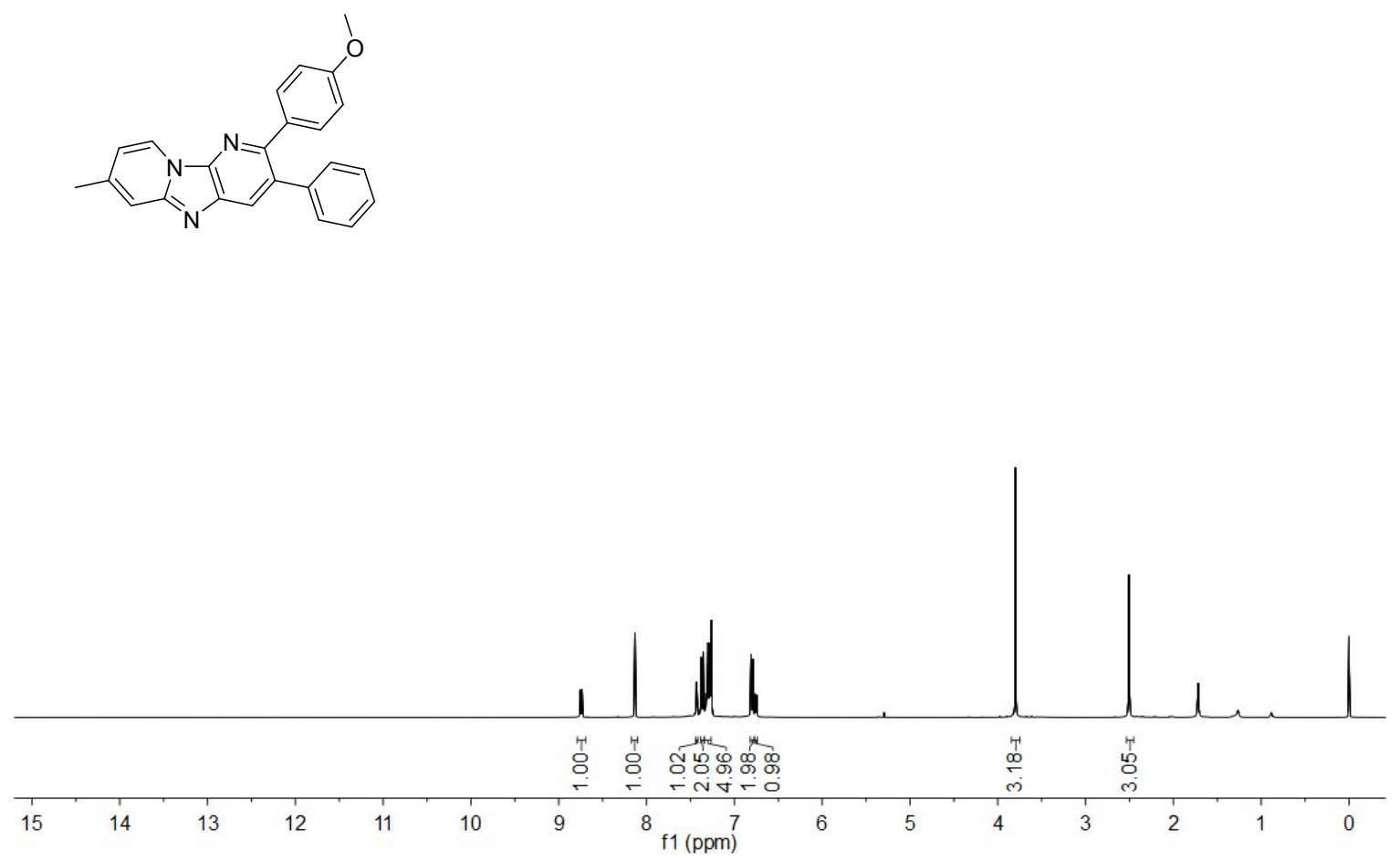

\section{${ }^{13}$ C-NMR for compound $6 f$}

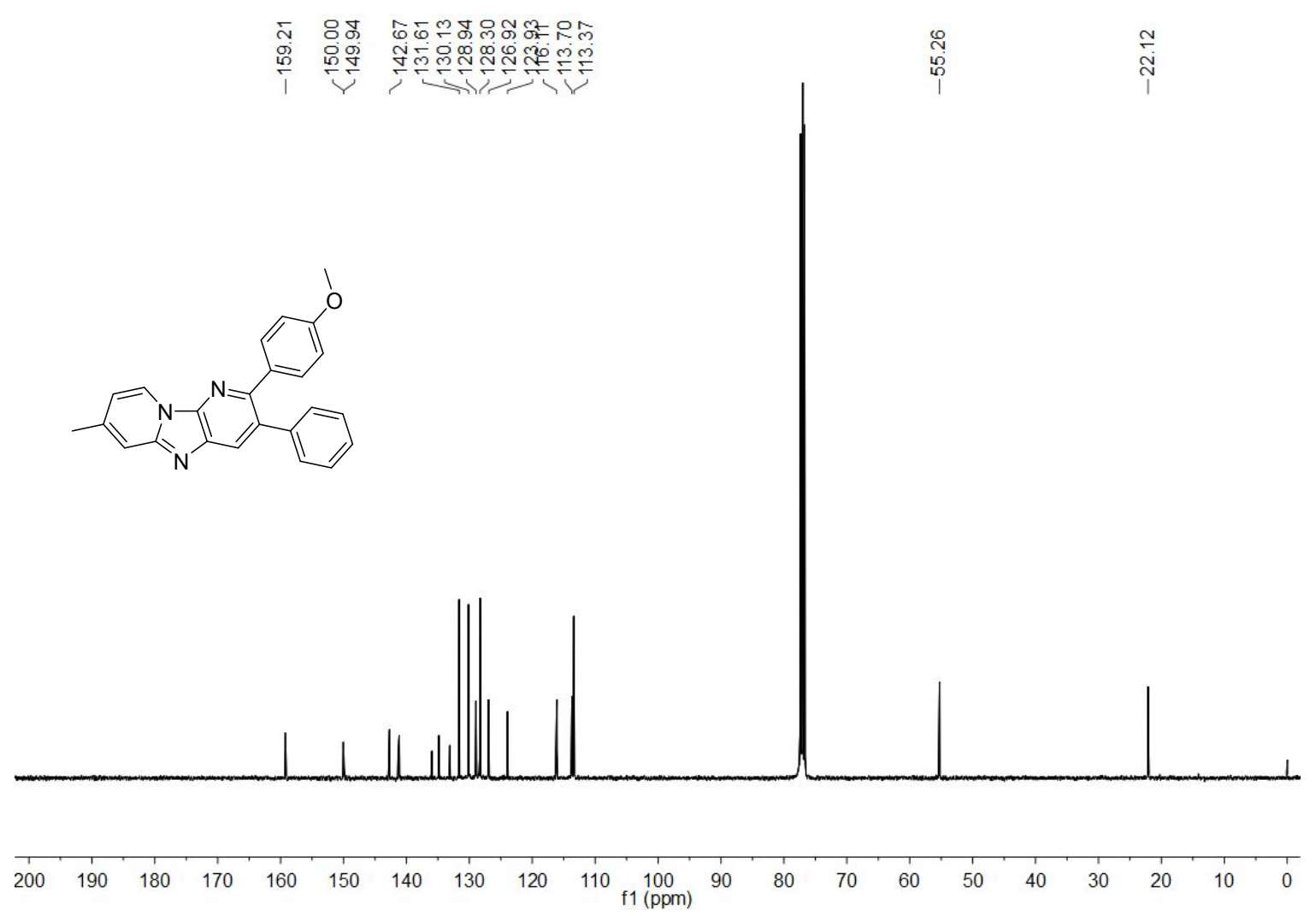


${ }^{1} \mathrm{H}-\mathrm{NMR}$ for compound $\mathbf{6 g}$

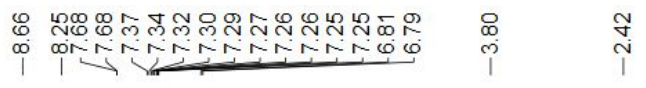<smiles>COc1ccc(-c2nc3c(cc2-c2ccccc2)nc2c(Br)cc(C)cn23)cc1</smiles>

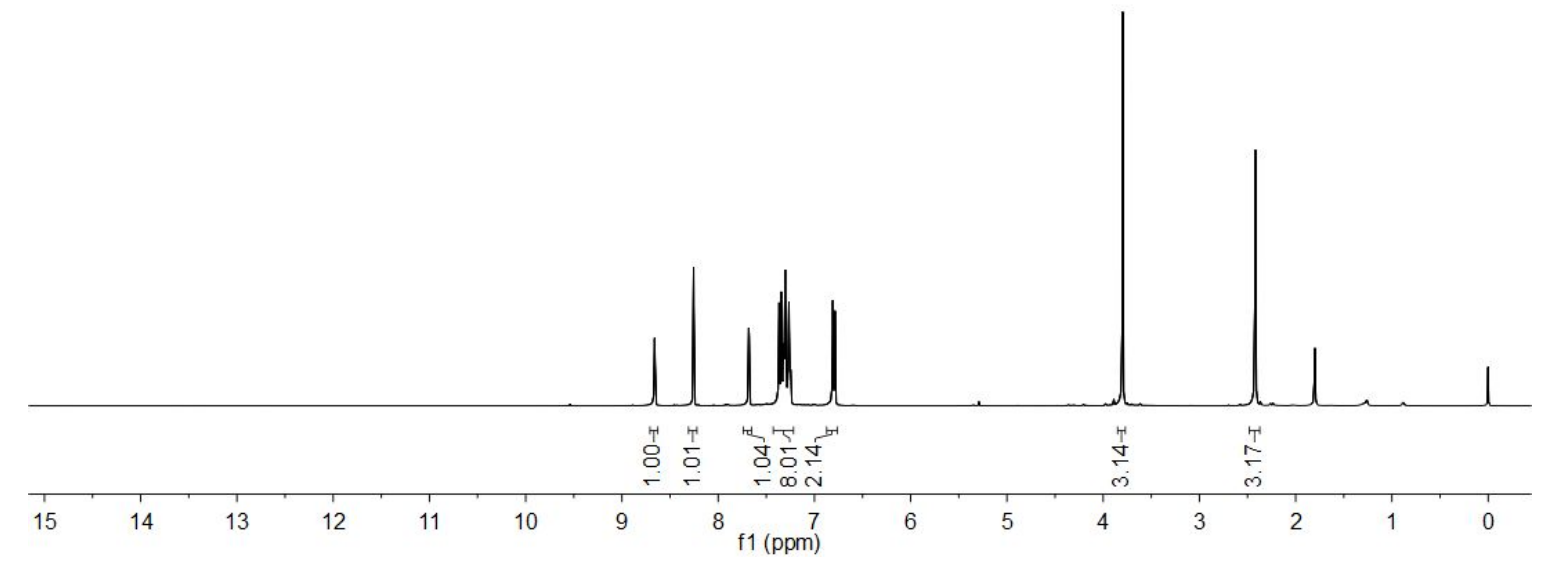

\section{${ }^{13} \mathrm{C}$-NMR for compound $6 \mathrm{~g}$}

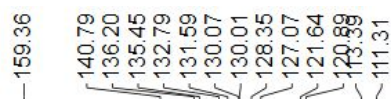

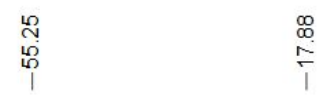<smiles>COc1ccc(-c2nc3c(Br)cc(C)cc3nc2C(Br)Br)cc1</smiles>

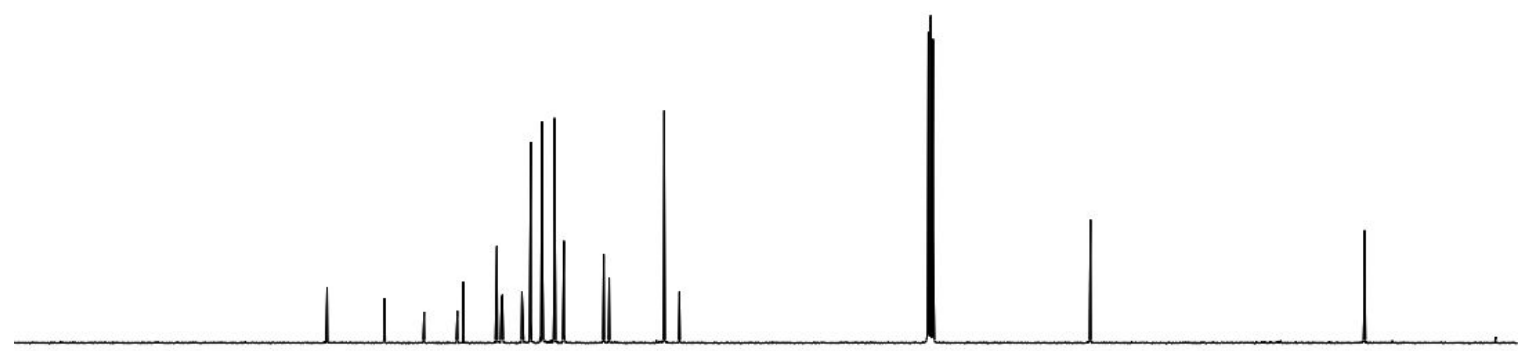

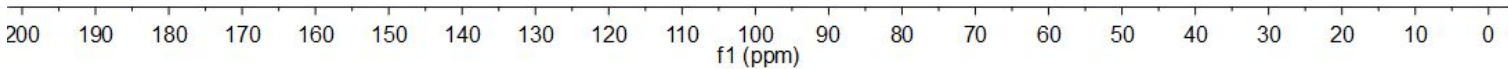


${ }^{1}$ H-NMR for compound $6 \mathrm{~h}$
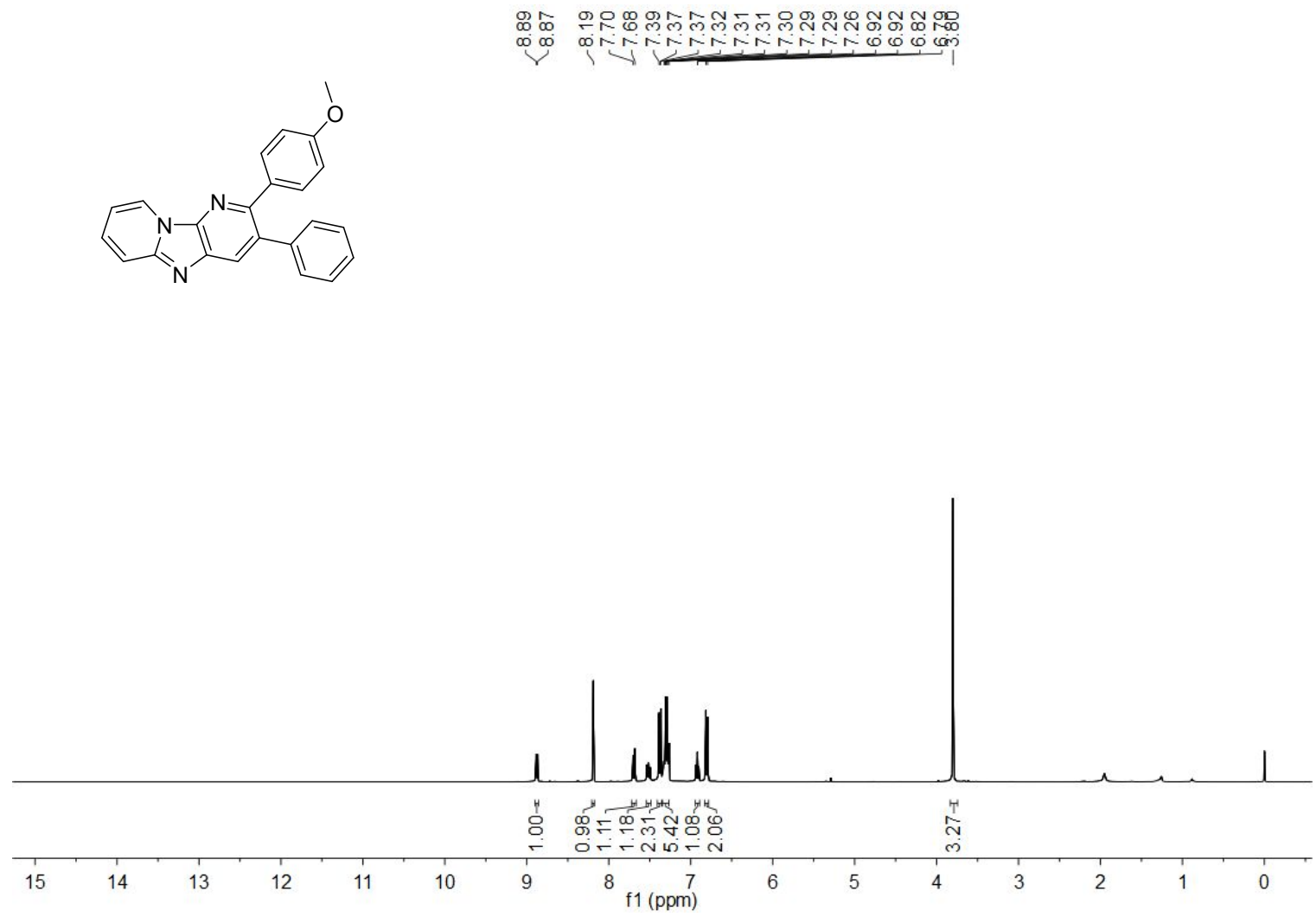

${ }^{13} \mathrm{C}-\mathrm{NMR}$ for compound $6 \mathrm{~h}$

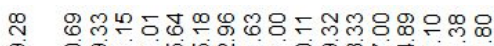

o

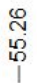
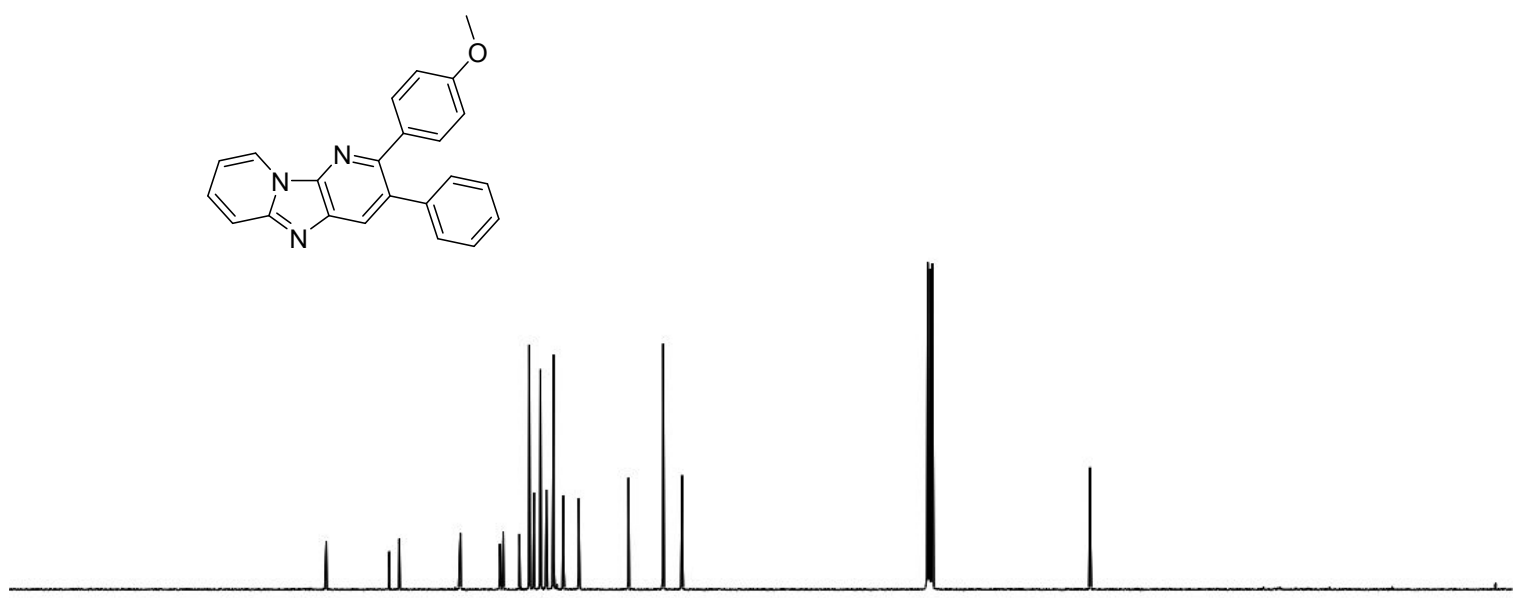

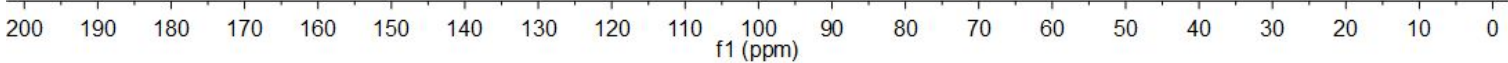




\section{${ }^{1} \mathrm{H}-\mathrm{NMR}$ for compound $6 \mathbf{i}$}

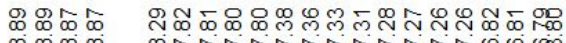

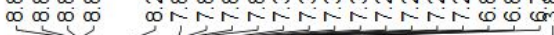<smiles>COc1ccc(-c2cc3nc4c(Br)cccn4c3nc2-c2ccccc2)cc1</smiles>

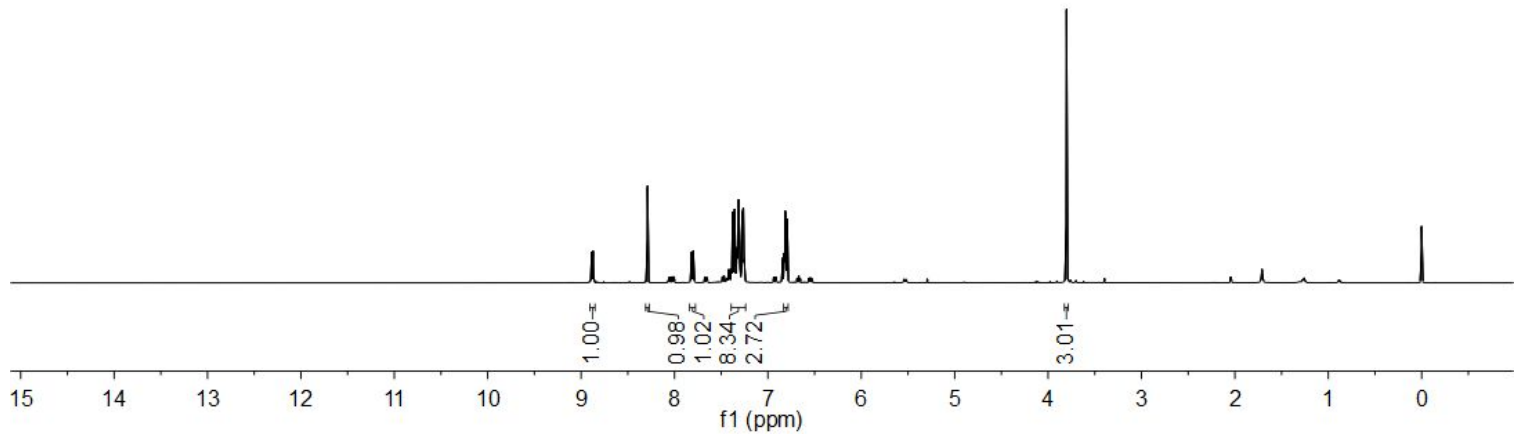

\section{${ }^{13} \mathrm{C}-\mathrm{NMR}$ for compound $6 \mathrm{i}$}

舟 ㅅำ

of

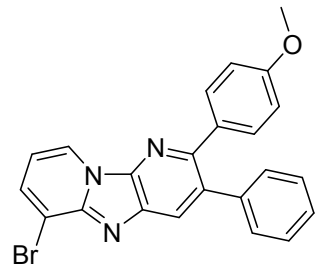

$\begin{array}{lllllllllll}00 & 190 & 180 & 170 & 160 & 150 & 140 & 130 & 120 & 110 & \begin{array}{l}100 \\ \mathrm{f} 1(\mathrm{ppm})\end{array}\end{array}$ 
${ }^{1}$ H-NMR for compound $6 \mathbf{j}$
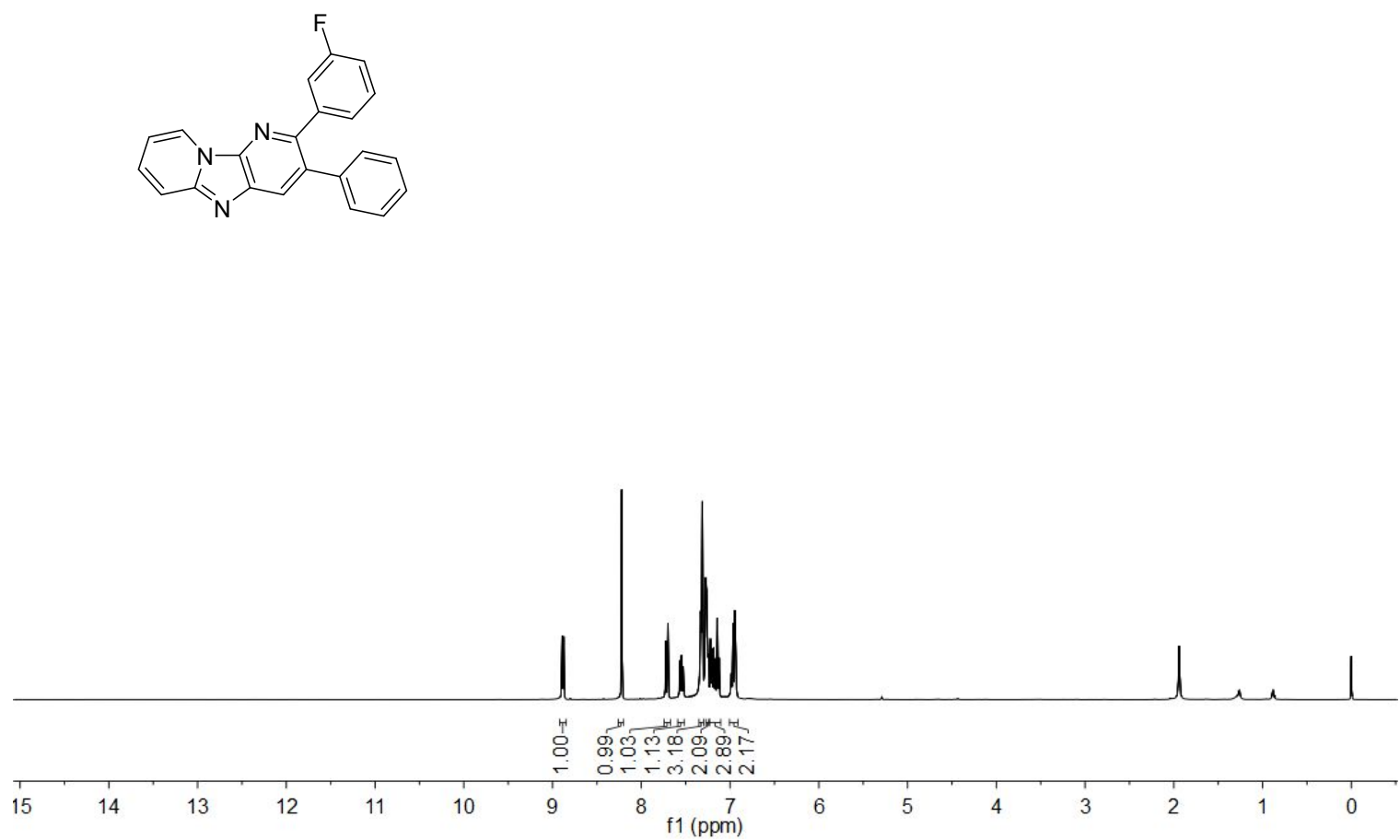

\section{${ }^{13} \mathrm{C}-\mathrm{NMR}$ for compound $\mathbf{6 j}$}

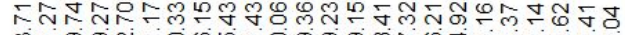

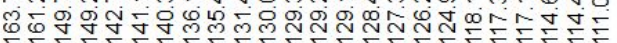
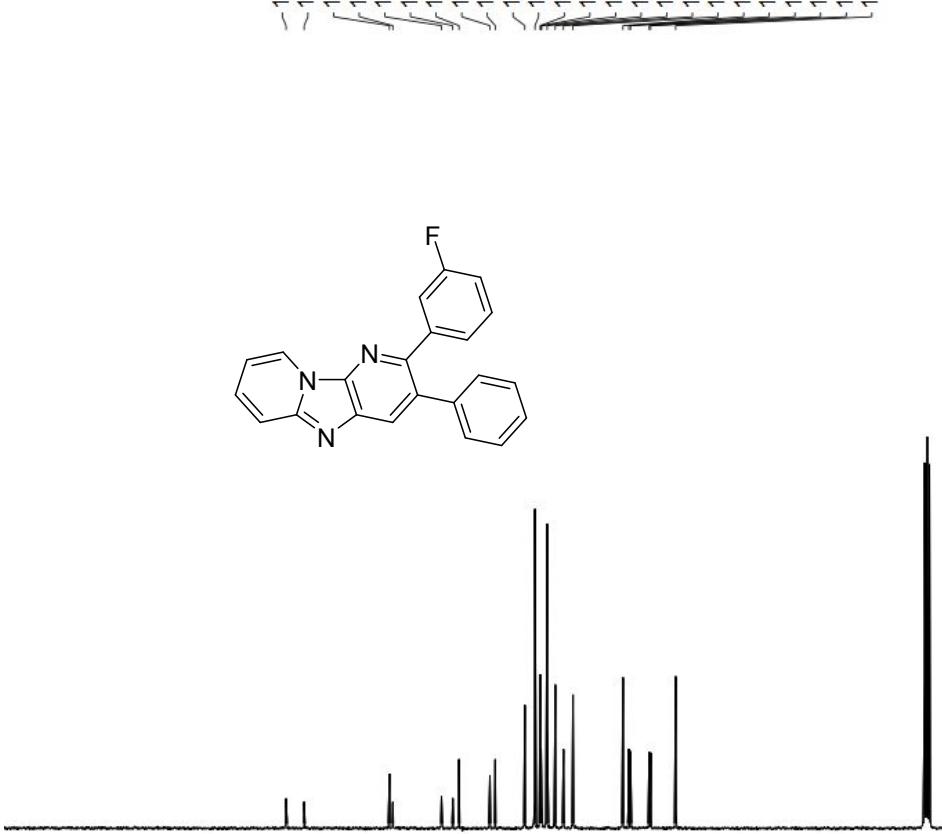

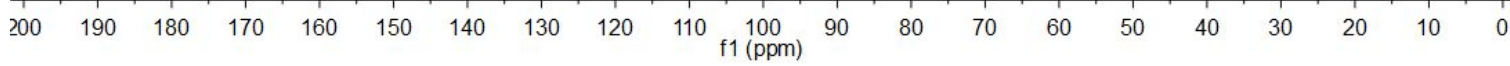


${ }^{1}$ H-NMR for compound $6 \mathrm{k}$

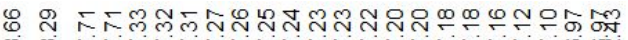

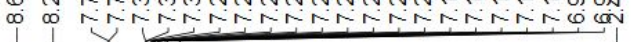<smiles>Cc1cc(Br)c2nc3cc(-c4ccccc4)c(-c4cccc(F)c4)nc3n2c1</smiles>

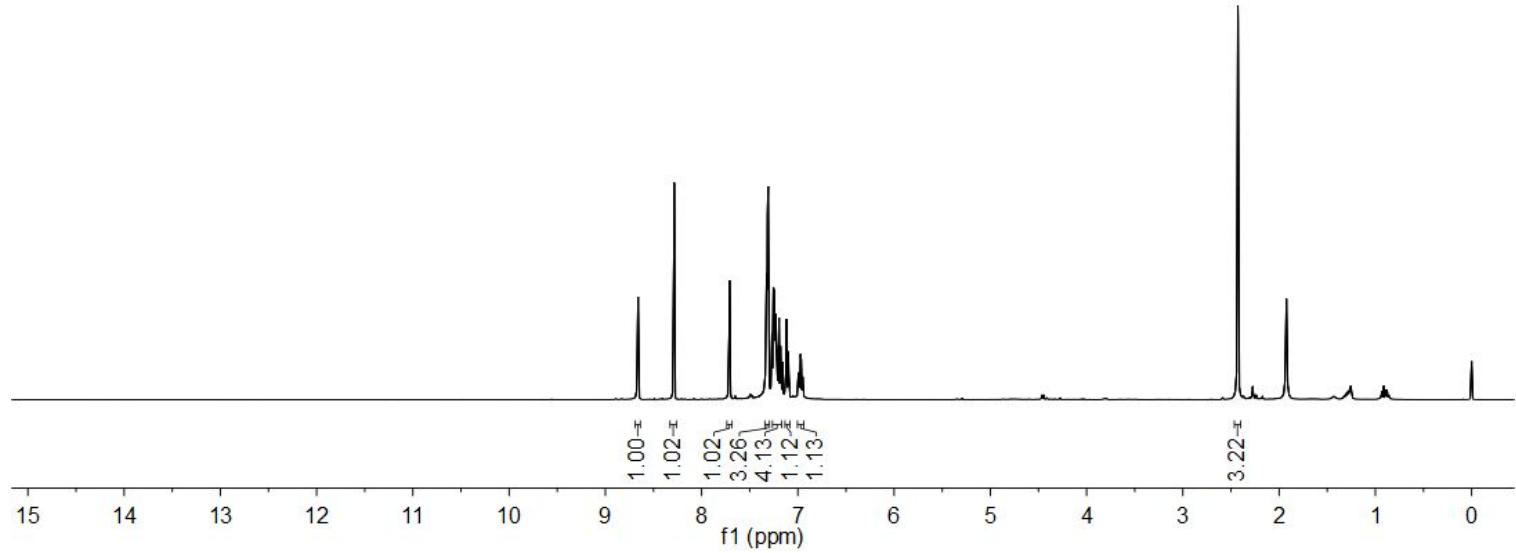

${ }^{13} \mathrm{C}-\mathrm{NMR}$ for compound $6 \mathrm{k}$

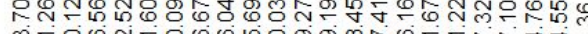

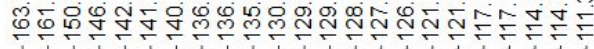

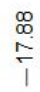<smiles>Cc1cc(Br)c2nc3cc(-c4ccccc4)c(-c4cccc(F)c4)nc3n2c1</smiles>

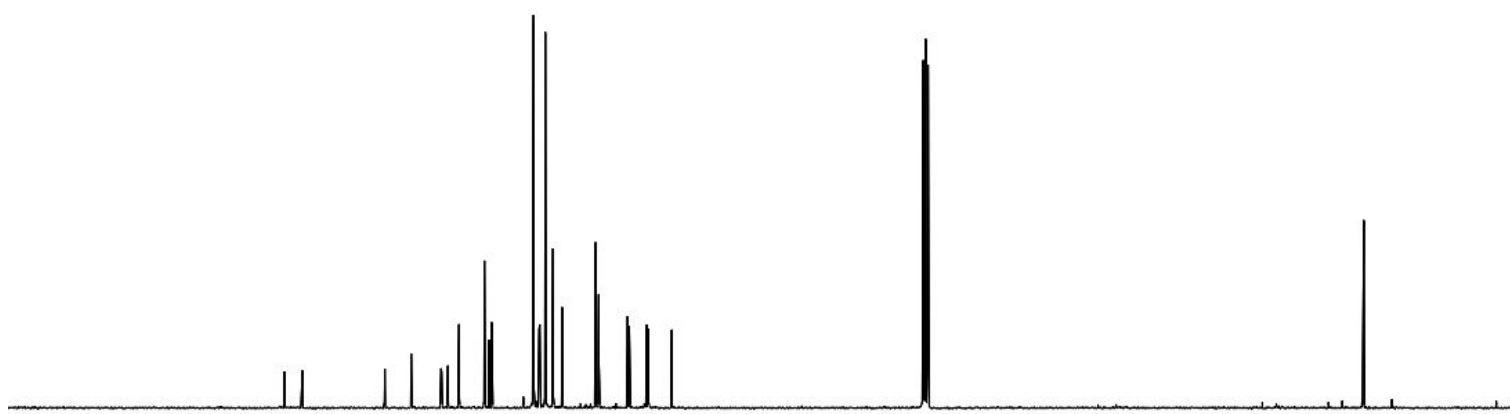

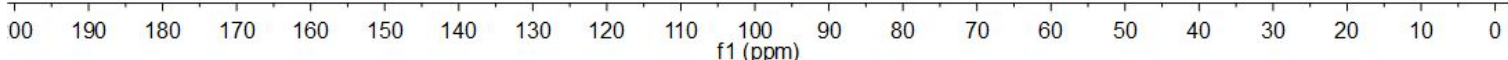




\section{${ }^{1} \mathrm{H}-\mathrm{NMR}$ for compound 61}

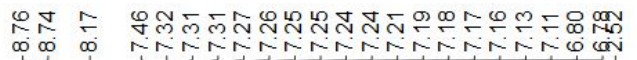

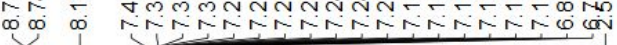
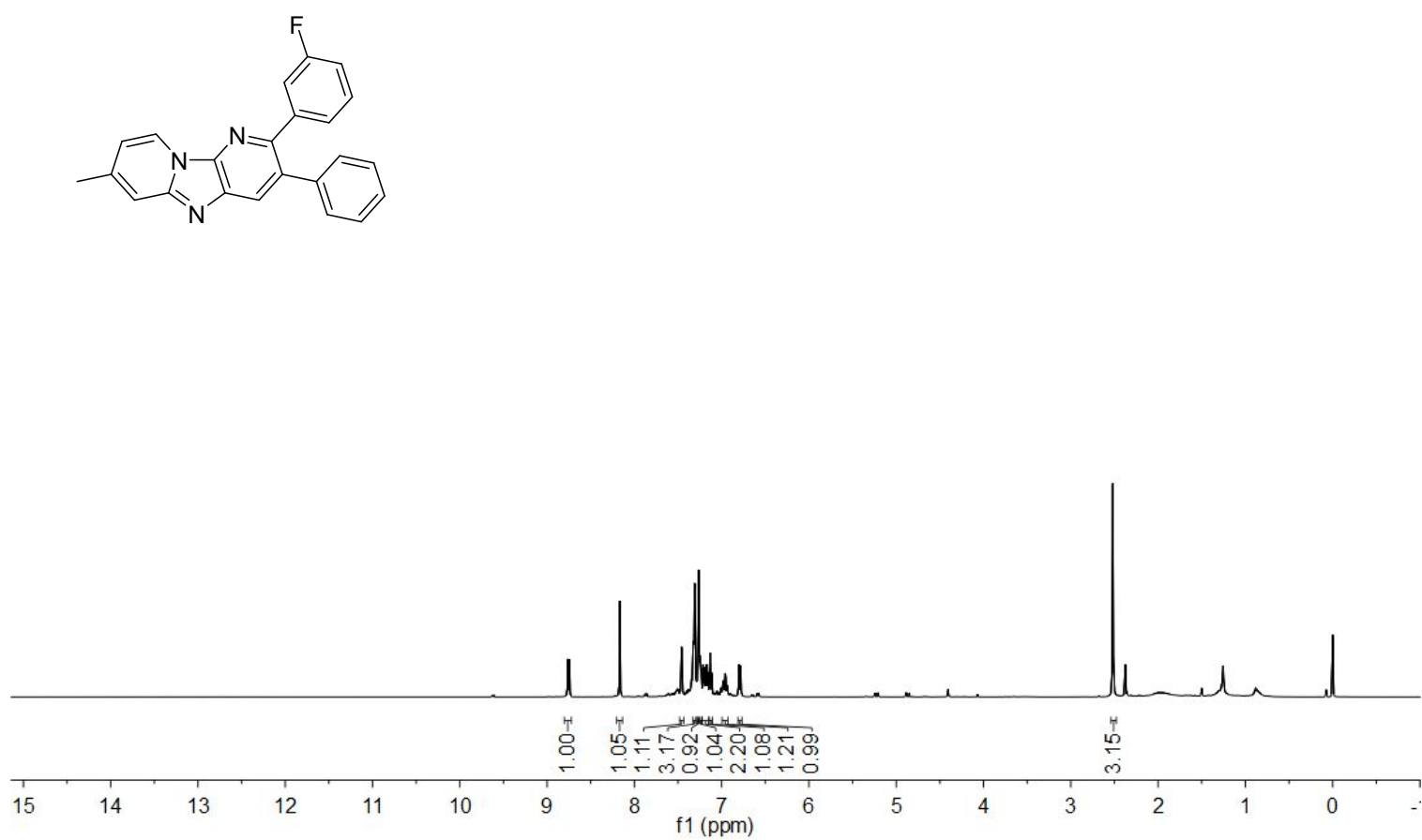

\section{${ }^{13} \mathrm{C}-\mathrm{NMR}$ for compound 61}
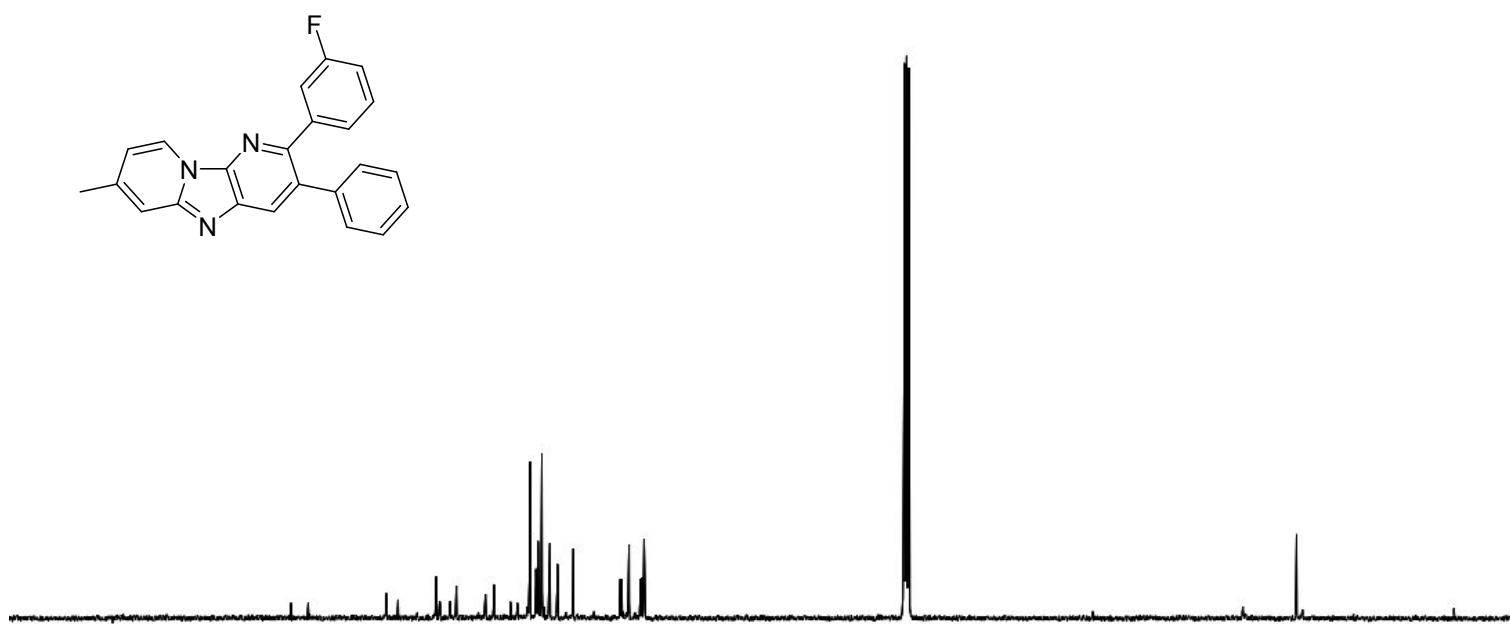
${ }^{1} \mathrm{H}-\mathrm{NMR}$ for compound $6 \mathrm{~m}$
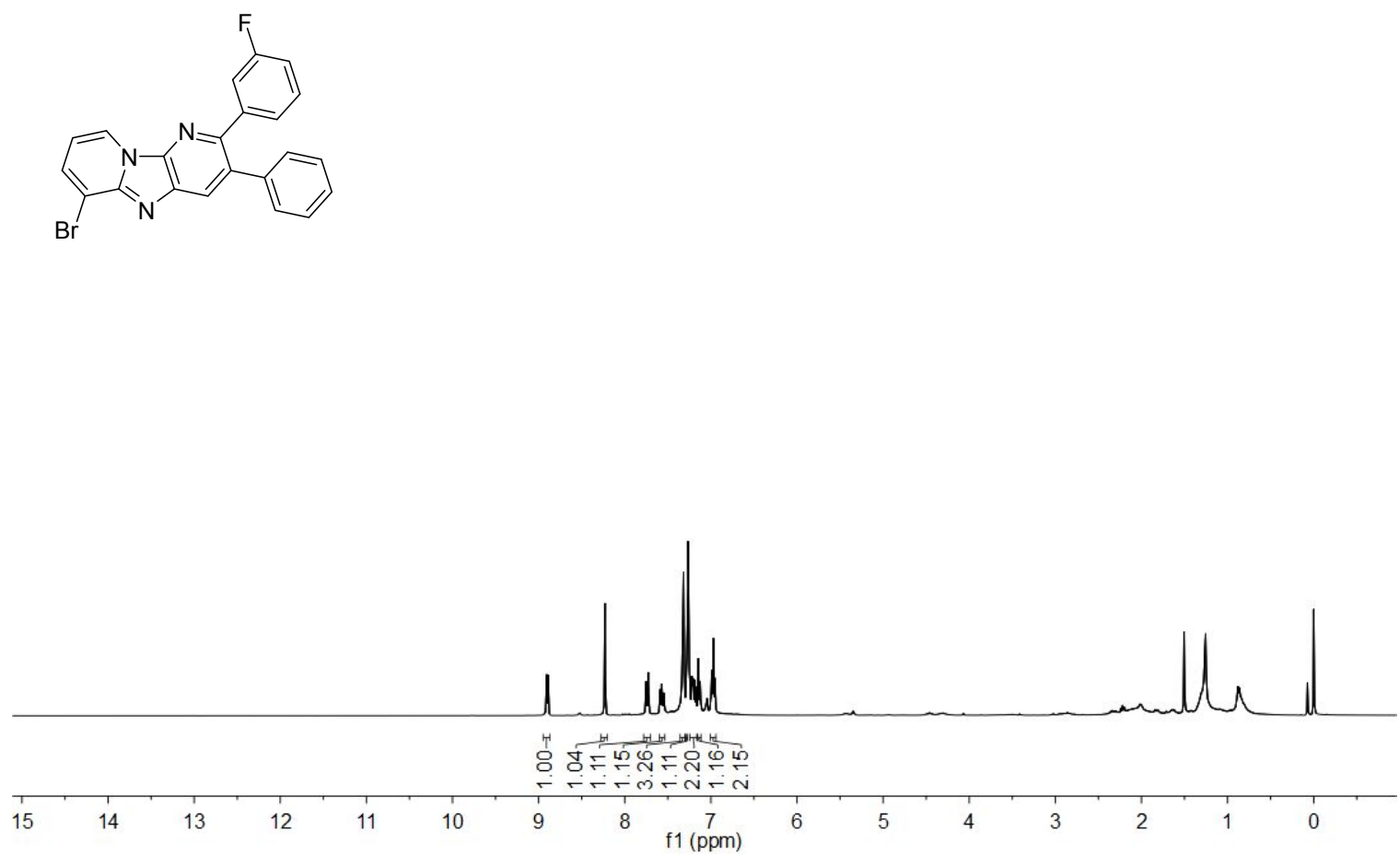

\section{${ }^{13} \mathrm{C}-\mathrm{NMR}$ for compound $6 \mathrm{~m}$}
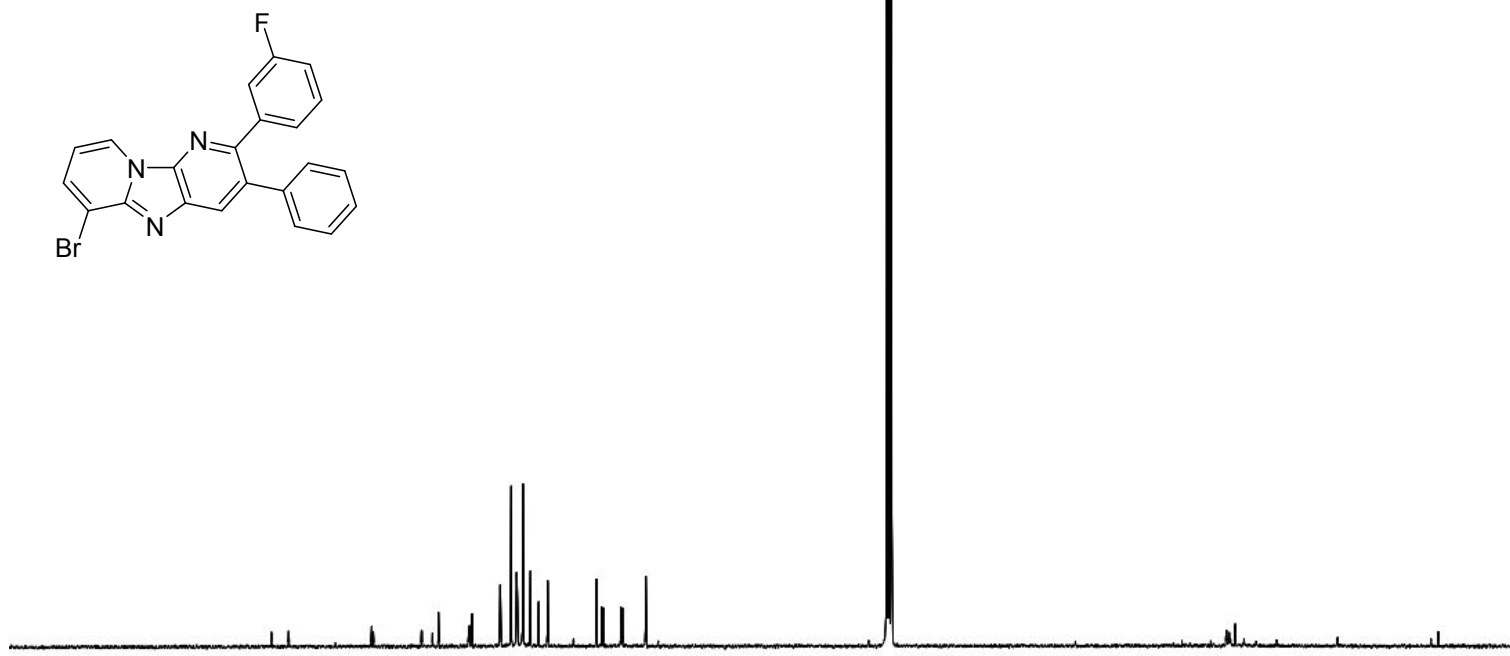

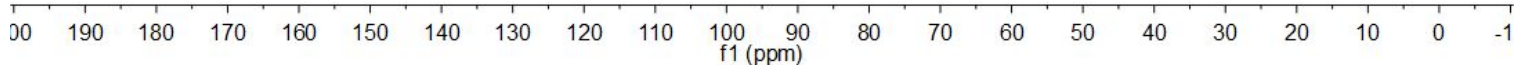


${ }^{1}$ H-NMR for compound 6 n<smiles>COC(=O)c1ccc(-c2nc3c(cc2-c2ccccc2)nc2ccccn23)cc1</smiles>

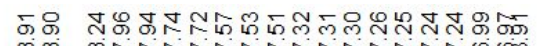

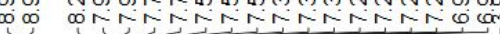

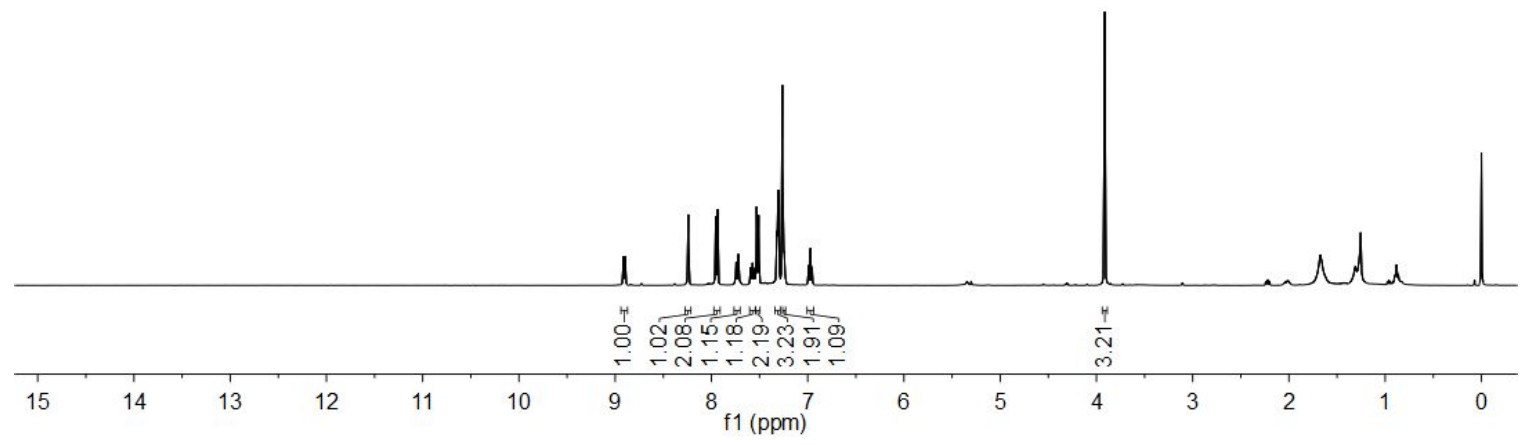

\section{${ }^{13} \mathrm{C}$-NMR for compound $6 \mathrm{n}$}

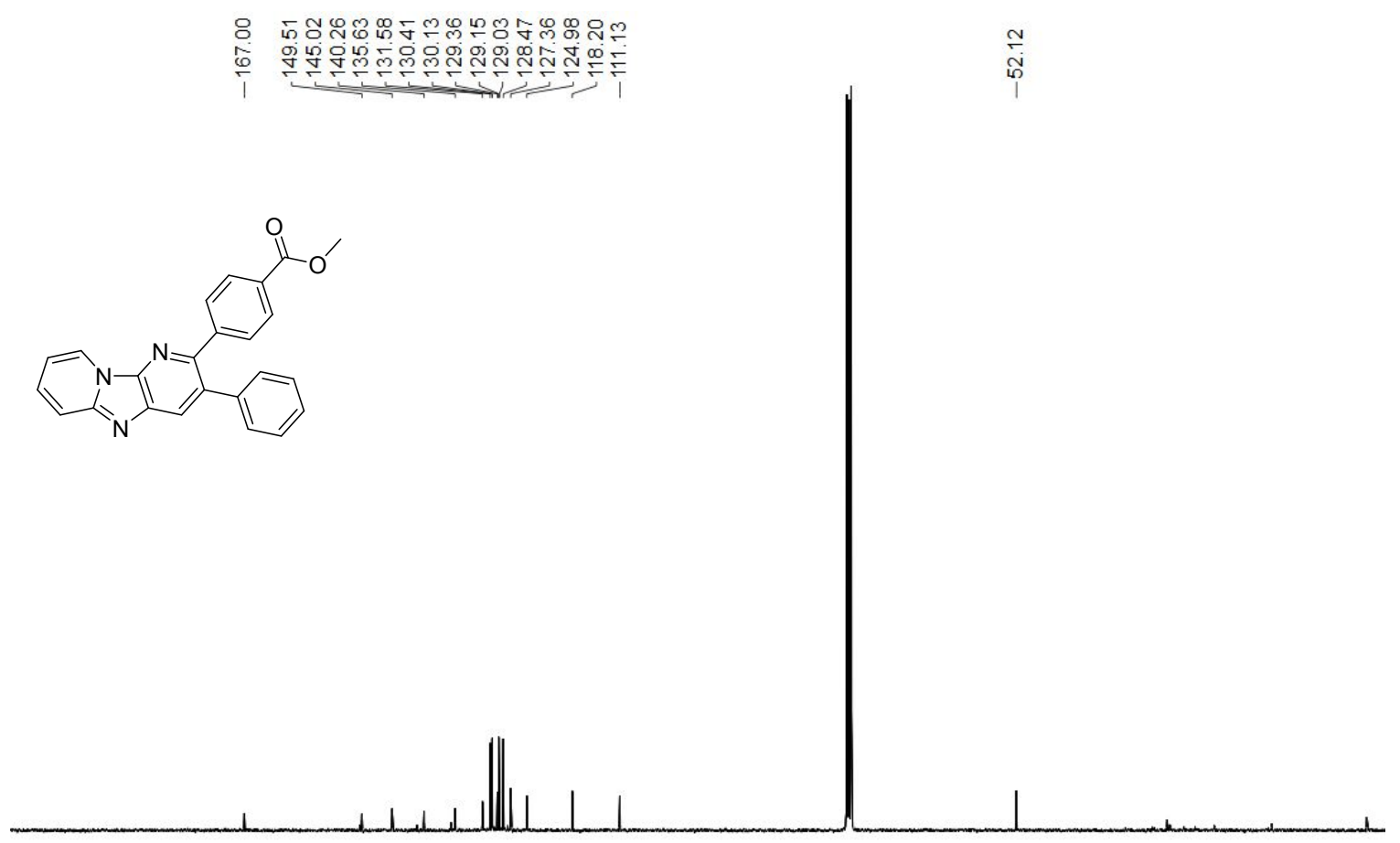

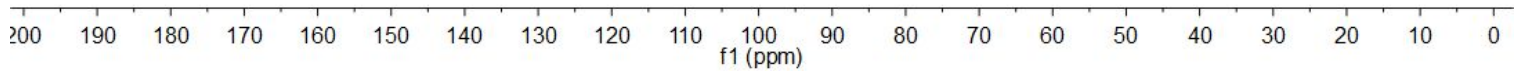




\section{${ }^{1} \mathrm{H}-\mathrm{NMR}$ for compound 60}<smiles>COC(=O)c1ccc(-c2nc3nc(C)cc(Br)c3nc2-c2ccccc2)cc1</smiles>

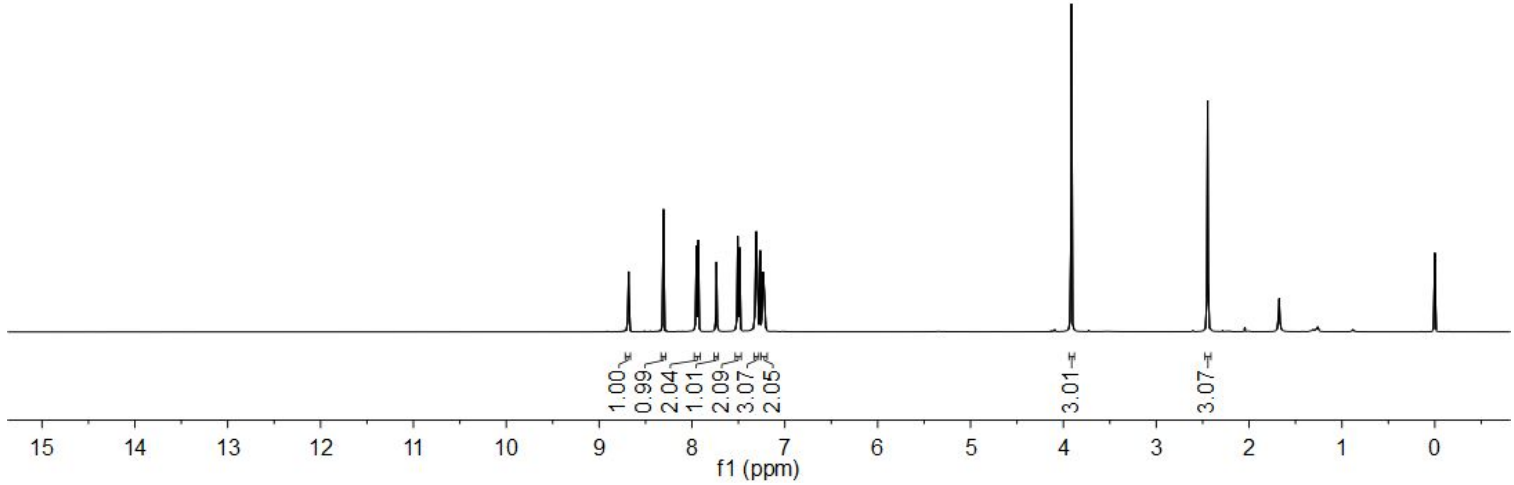

\section{${ }^{13} \mathrm{C}$-NMR for compound 60}
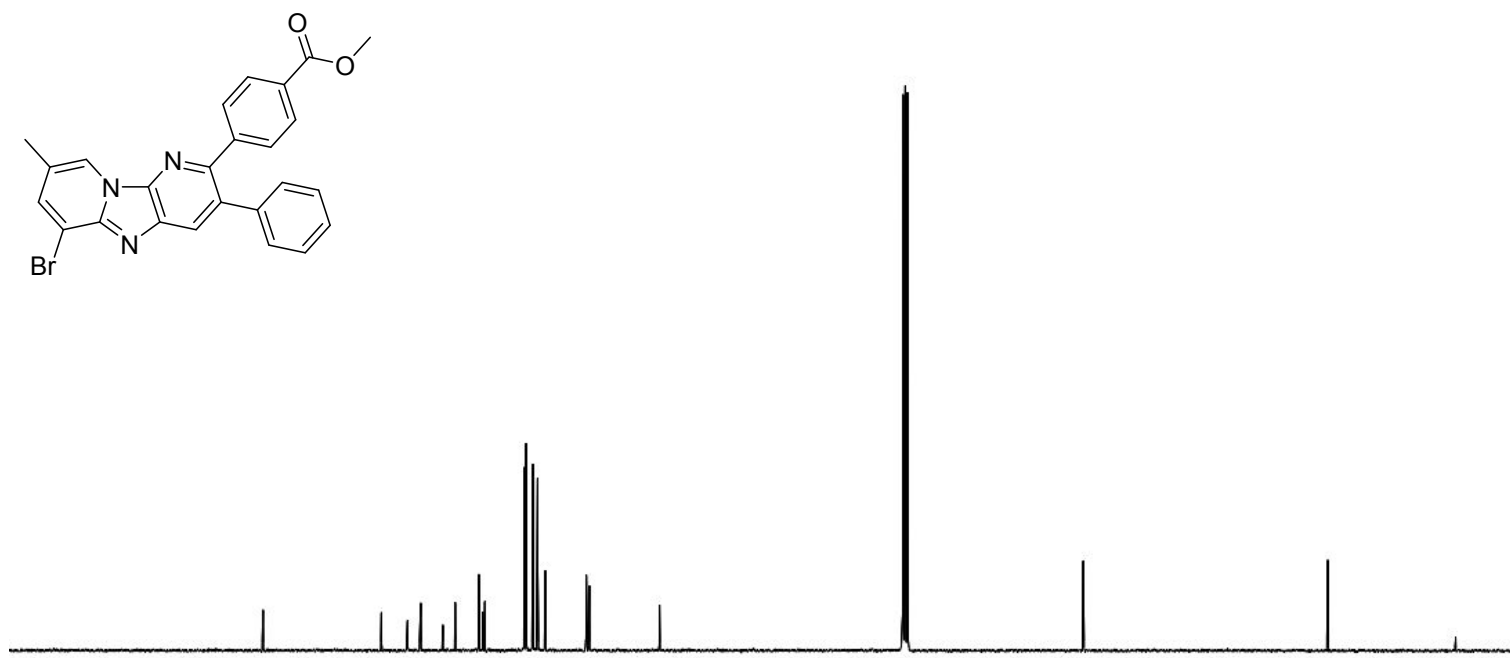

20

$\begin{array}{lllllllllll}190 & 180 & 170 & 160 & 150 & 140 & 130 & 120 & 110 & \begin{array}{l}100 \\ \mathrm{f} 1(\mathrm{ppm})\end{array}\end{array}$ 
${ }^{1}$ H-NMR for compound Ta

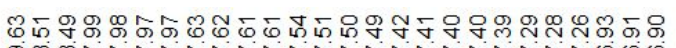

(1)
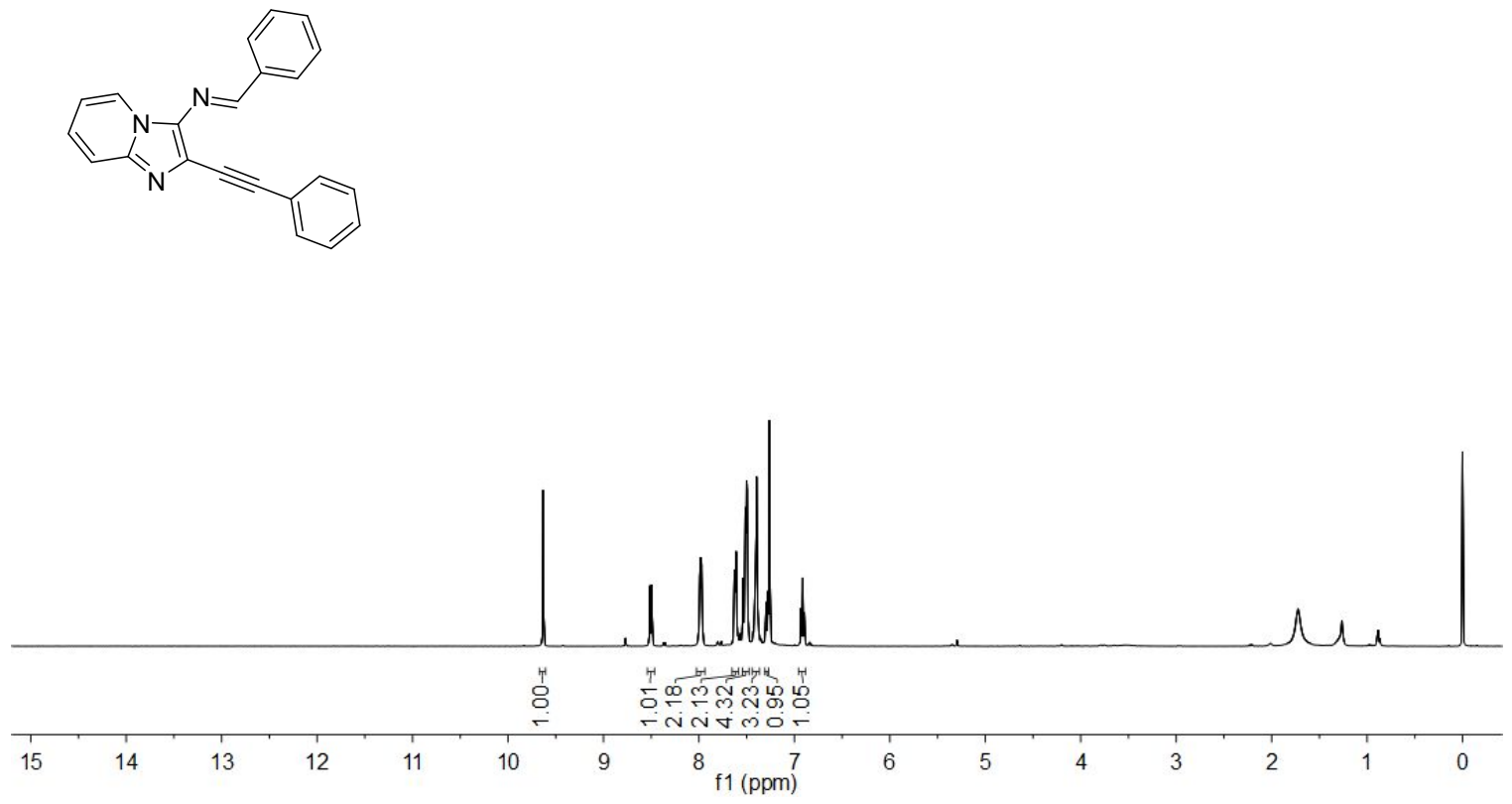

${ }^{13} \mathrm{C}$-NMR for compound $7 \mathrm{a}$
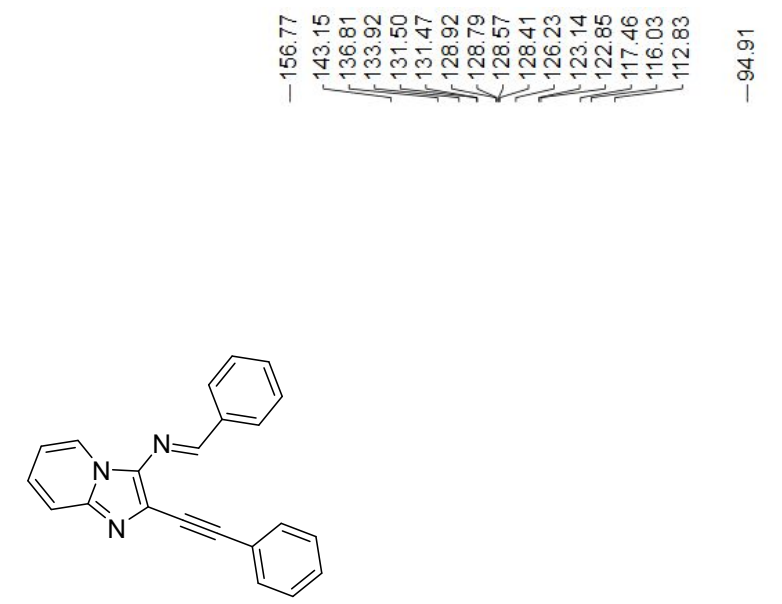

$\underset{\substack{n \\ \infty}}{\substack{0 \\ 0}}$
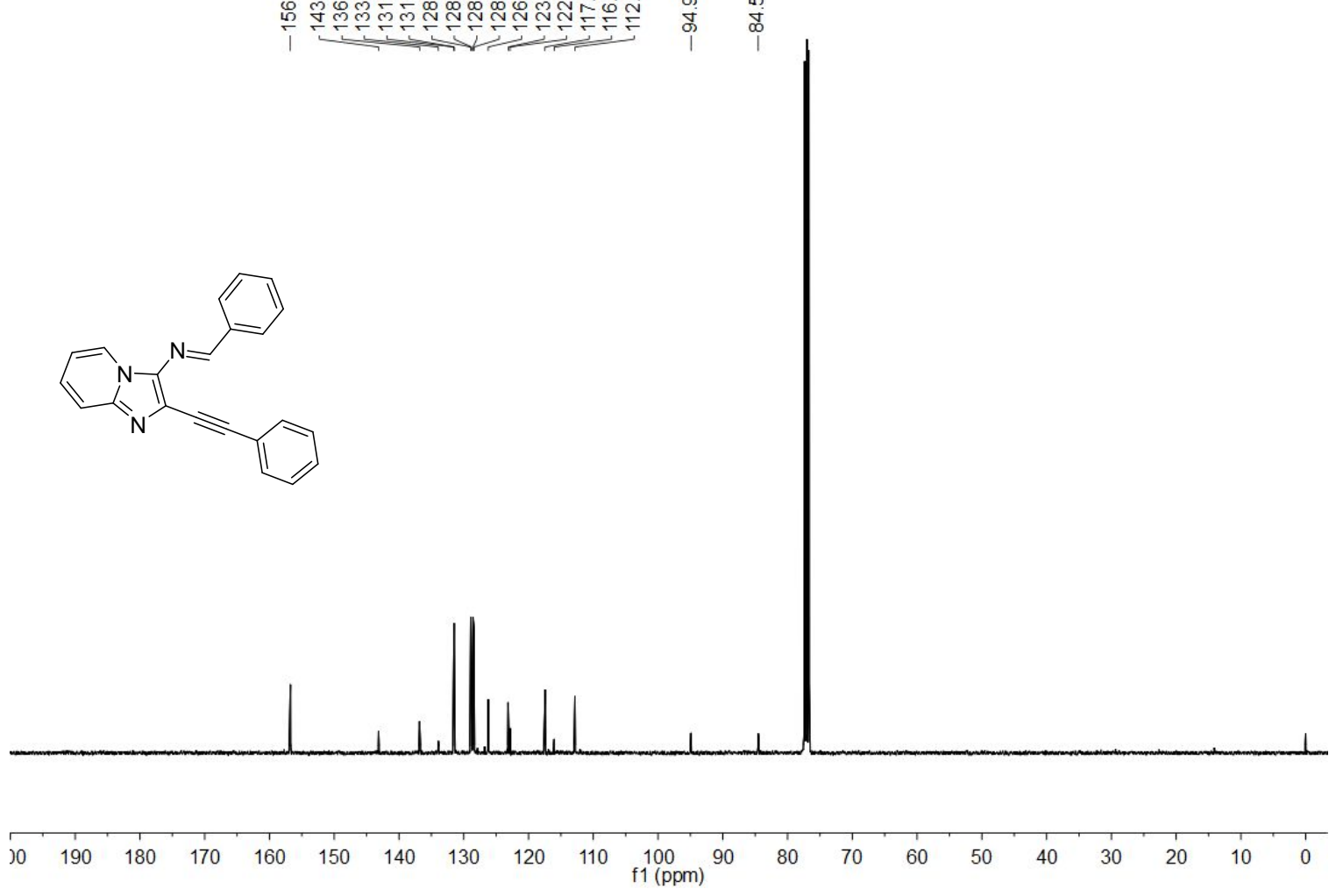

S22 
${ }^{13}$ C-NMR-DEPT135 for compound 7a

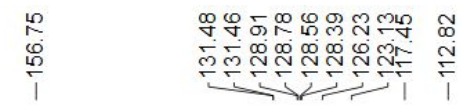
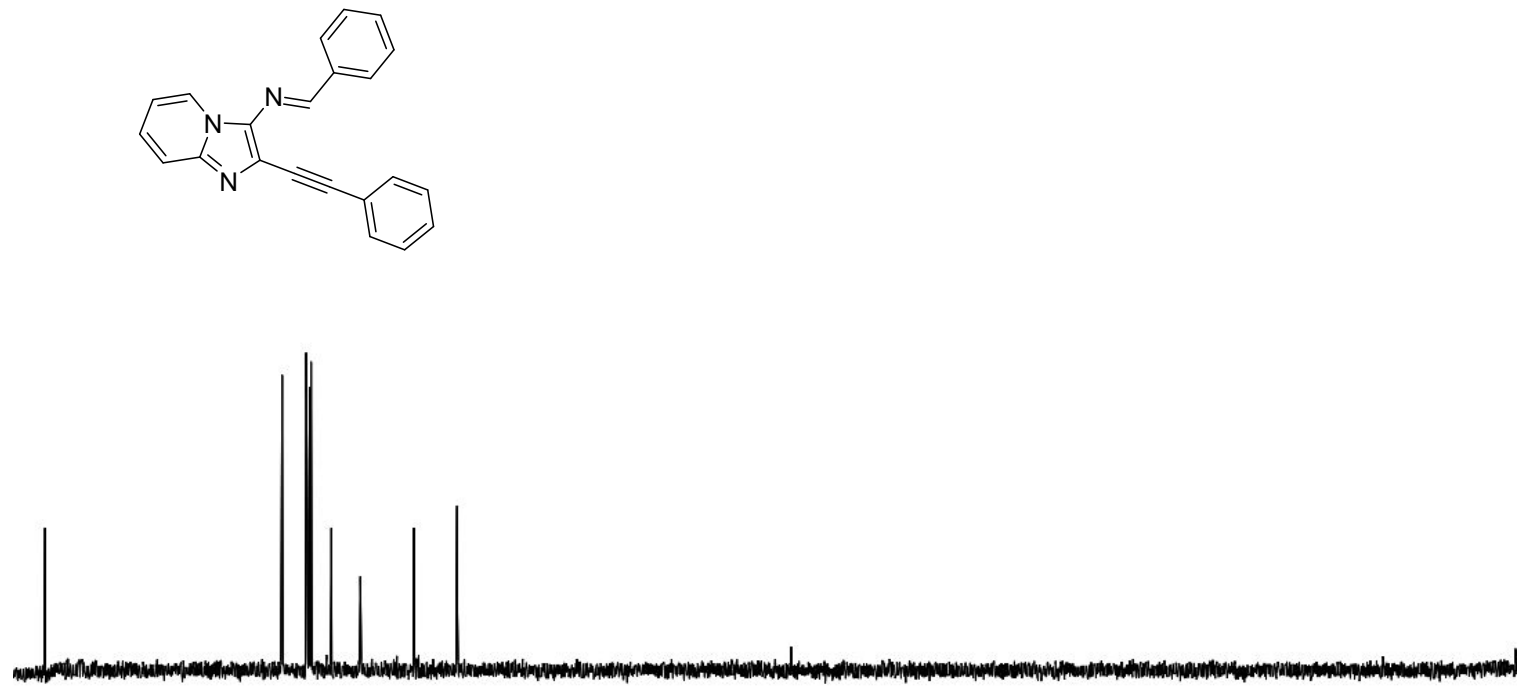

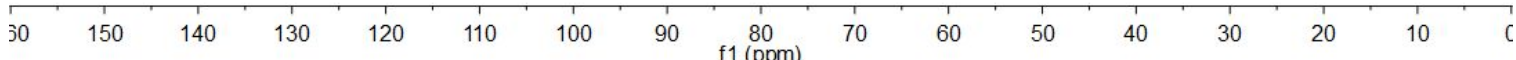

